\title{
Illuminating Villages and Minds in Rural Peru
}

\author{
Hannah Beatty \\ Graduate Student, Department of Civil, Construction, and Environmental Engineering \\ The University of Alabama \\ Tuscaloosa, AL 35487 \\ beatt005@crimson.ua.edu \\ Dr. Pauline Johnson \\ Professor, Department of Civil, Construction, and Environmental Engineering \\ The University of Alabama \\ Tuscaloosa, AL 35487 \\ paulinej@eng.ua.edu \\ Dr. Philip W. Johnson, P.E. \\ Associate Professor, Department of Civil, Construction, and Environmental Engineering \\ The University of Alabama \\ Tuscaloosa, AL 35487 \\ pjohnson@eng.ua.edu \\ Dr. Beth Todd \\ Associate Professor, Department of Mechanical Engineering \\ The University of Alabama \\ Tuscaloosa, AL 35487 \\ btodd.eng@gmail.com
}

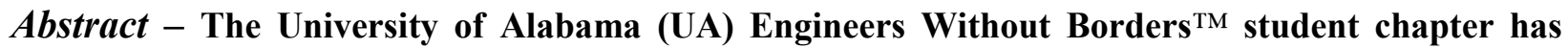
been working for four years with several remote villages in the Amazon Basin in Peru. During the 2006 evaluation project students interviewed villagers and conducted testing to determine the most pressing infrastructure needs: safe water, septic systems, lighting, and communications. In the third year, 2008, a student team began to address the lighting problem by working with the villagers to install photovoltaic solar panels in Amazonian villages. These test installations have been monitored by in-country NGO project collaborators and will continue to be field-evaluated.

Meanwhile identical solar units were evaluated in a controlled study at UA during the months of July through September of 2009. The photovoltaic panels were assessed for voltage and current variation with surface and ambient temperature, varying cloud cover and precipitation events. System light outputs were evaluated for luminance. As a whole the systems were also judged based on their performance in on-site operation, maintenance, sustainability and environmental impact. The systems were rated using a comparative weighting and scoring table. Based on the results of the study, two of the systems evaluated were found suitable for large-scale deployment in areas such as the Amazonian region in Peru.

Assessing the experience in a post-trip survey, students identified the particular strengths of the program as the development of teaming, communications, and experiential learning skills.
\end{abstract}

Index Terms- developing countries, renewable energy, rural areas, solar photovoltaic systems 


\section{INTRODUCTION}

Throughout the developing world there is a desire for rural electrification. While connecting to the power grid may be one solution for densely populated urban settings, it is inappropriate for remote developing communities. Rural villages and towns are often too far away from the closest grid to make connection economically feasible, and their populations are often too poor to afford connection, service, and user fees. Rural villages present significant challenges, but they also provide opportunities to develop sustainable, safe alternative technologies.

Developing countries and non-profit organizations are working to find alternative ways to electrify rural regions. A popular emergent sustainable energy alternative is solar power. Solar panels operate independently from the grid (photovoltaic effect), require little maintenance, and leave a relatively small carbon footprint. However, the upfront costs are burdensome for lowincome households. In this study a pilot community installation and comparative campus study of three commercially available photovoltaic (PV) systems was conducted, and student learning outcomes were assessed. The intent of the studies is to give developing communities, governmental and non-governmental organizations and related groups helpful insights on similar projects.

\section{BACKGROUND}

Starting in 2005 the University of Alabama student chapter of Engineers without Borders (EWB) has partnered with the Loreto Program of Nature and Culture International to install small-scale infrastructure projects in developing communities near Iquitos, Peru. Nature and Culture International is a Non Government Organization (NGO) that builds partnerships with community stakeholders to restore and function sustainably in threatened ecosystems concomitant with the community culture. The four villages so far included in the Alabama EWB efforts are populated by peoples of mixed heritage most of whose progenitors arrived as workers during the rubber boom and stayed on as hunter gatherers. The villages all border Amazonian tributaries and are populated by up to 40 Spanish-speaking families. Each village is centered on a rough soccer pitch surrounded by the elevated houses built of palm thatch and hand sawn lumber. Typically the village has two public buildings: a school and a community center, in some cases built of concrete masonry units with galvanized roofing, but in most cases built of wood and thatch like the homes. The government hierarchy includes a village Mayor and additional named officials and cultural protocols are respected and when working in villages. The economy revolves around fishing, sale of renewable forest products, such as palm fruit, and sale of handicrafts, some of which have recently made it as far as fine museum shops in the United States through the efforts of our NGO collaborators.

The villages are four hours or more by high-speed boat from the nearest population center at Iquitos. There are no roads and no vehicles owned by the village other than canoes. There is no reliable source of clean water, no septic systems, no telephones, and home lighting is generally limited to small open-wick kerosene lamps. The weather is uniformly warm, but during the rainy season the countryside floods and villagers can paddle up to their doorsteps. And during the dry season the tributaries the villages border often dry up into small streams.

The first EWB trip to the area in the summer of 2006 was an assessment trip in accordance with EWB national protocol. It was also offered for course credit. The goal was to investigate potential relationships with the villagers and determine if there were appropriate projects for future years. The students brought surveying instruments and soil testing equipment and 
developed layout maps of two villages, did soil percolation and water tests and did a site selection study for a wildlife observation tower in a nearby reserve. In public and private discussions the villagers and village leaders presented a convincing case that they need a reliable source of clean water, sanitary systems, lighting, and communications with the outside world. The interviews, soccer games and resultant friendships were powerful, effectively summed-up by a student comment, "Changed forever by Peru!" Students committed to a follow-up trip during the summer 2007, during which they installed a public generator for village lights and the first public toilet in Chino. In all cases villagers worked alongside us on manual aspects of the projects.

For the third trip in the summer of 2008 the student participants developed a catalog of possible projects to meet the villagers' needs, considered the constraints they were under, and decided to do a test installation of low-power solar lights.

These trips were organized as for credit, service-learning classes, structured around the Engineers Without Borders model that integrates interdisciplinary engineering service learning with community partners, practitioner oversight, and faculty mentoring. The benefits of global experiences for students include development of leadership, teaming, management, communication, and cross-cultural skills; flexibility, adaptability, maturity, independence, and the ability to analyze, adjust to, and appreciate local customs and cultural contexts; the acquisition of a global perspective, appreciation of the societal implication of their work, and the satisfaction of working with a client to take an international community project from conception and planning through installation. Experience abroad forces students to deal constructively with cultural differences and situations they would not otherwise face.

The current study is a follow-up to the field installations that were done in the summer of 2008 , follow on student evaluations ${ }^{1}$, and the serial lab study set up and performed at UA in 2008-2009. 


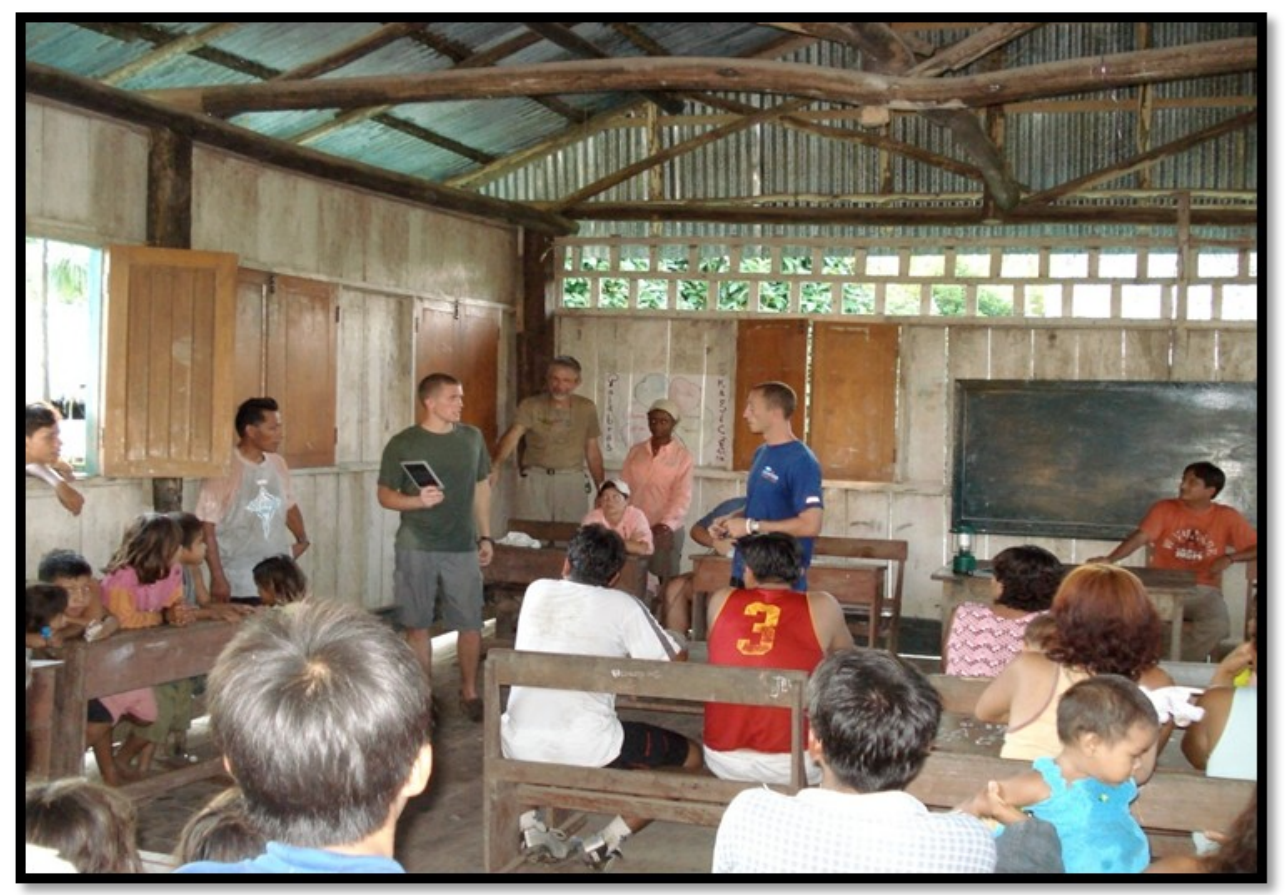

FIGURE 1

IN THE LOCAL SCHOOLHOUSE, STUDENTS EXPLAIN AND DEMONSTRATE OF HOW THE PANELS CHARGE THE LIGHTS .

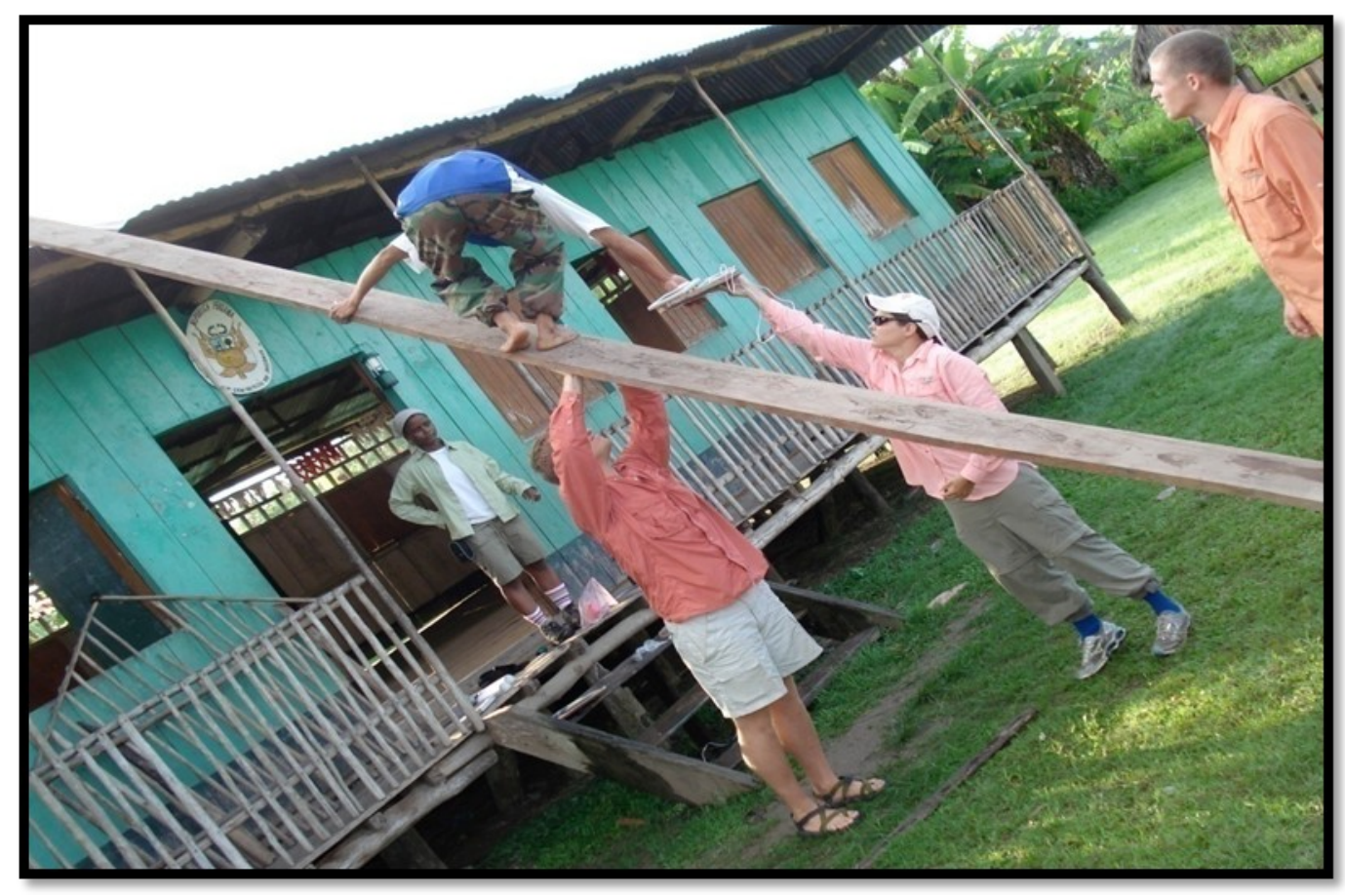

FIGURE 2

Villagers and students install panels in the village of Nuevo Hunin. 


\section{Мethod}

During the 2008 expedition the villagers and the EWB team installed eighteen PV systems (3 types, 2 of each type, a total of 6 per village) on the roofs of community buildings in three remote villages with no modern amenities (Figures 1 and 2). The three systems selected were The Designers Edge L-949 Rechargeable Solar Powered Shed Light, Sunforce Solar Shed Light, and Solar Camping Lantern made by LEDtronics Inc. These systems were chosen because of their low costs and ease of installation and operation. The current study was conducted in order to determine whether or not these systems are sufficiently reliable and operable for larger-scale installation in rural areas in Peru and throughout the developing world. Reliability and operability are, of course, only a small part of the entire sustainability issue associated with the lights. Additional ongoing questions that are being addressed include life cycle costs, battery disposal, recycle and disposal of other component, on-site maintenance and replacement, and the cultural ramifications of indoor lighting.

A follow-up study on the systems installed in Peru was conducted at The University of Alabama during the summer of 2009 to evaluate the short-term reliability, operability and output. A total of 30 systems were tested (10 of each system). The panels were mounted on a frame that replicated a typical galvanized metal roof on a community building in the Amazonian region of Peru, as shown in Figure 3. In order to eliminate as many shadows as possible, this structure was fixed to the roof of a three-story building on the campus of The University of Alabama. For optimal output, the panels faced south at an angle of $18^{\circ}$. This was determined by subtracting $15^{\circ}$ from Tuscaloosa's latitude ${ }^{2}$. In Peru the panels were installed directly onto a north-facing roof and pointed almost directly upward as is appropriate close to the equator. A slight angle was used to allow for washing by rain. After the Tuscaloosa panels were installed, they were connected through a protective conduit to a computer in a lab below to record voltage and current data. Panel and ambient temperatures were recorded using thermocouples and data loggers placed under the frame. Temperatures were recorded because previous studies have shown that panel efficiency tends to decrease as temperatures increases ${ }^{3}$.

Light output was measured with a light meter recording in LUX. The tests were carried out in a covered dark-box. The light and the light meter were fixed approximately 20 inches apart and $7 \frac{1}{2}$ inches above the base of the box. Light measurements were recorded in 15-minute increments. These tests lasted between 1 and 4 hours. The lights of the systems were evaluated according to their short-term and long-term outputs (figures 14-17).

This study occurred during July, August, and September of 2009 at The University of Alabama campus in Tuscaloosa. During this period Tuscaloosa averages $52 \%$ cloud cover ${ }^{4}$, about 11 inches of rainfall, and has daytime temperatures in the $80 \mathrm{~s}$ to $90 \mathrm{~s}$. The conditions experienced during this period best reflect the rainy season of northern Peru along the Amazon River. The rainy season in the Amazonian region of Peru takes place between November and March with temperatures in Fahrenheit ranging from the low 80's to the upper 90's during the day ${ }^{5}$. According to the NASA renewable energy resource website (Surface meteorology and Solar Energy), the Peruvian Amazon averages 76\% cloud cover and receives an average of 52 inches of rain during the rainy season ${ }^{6}$. To assist in determining the appropriateness of the systems, key aspects were identified and scored with respect to their comparative performance and perceived importance. The systems' performance in these aspects will be discussed in later sections of this paper. 


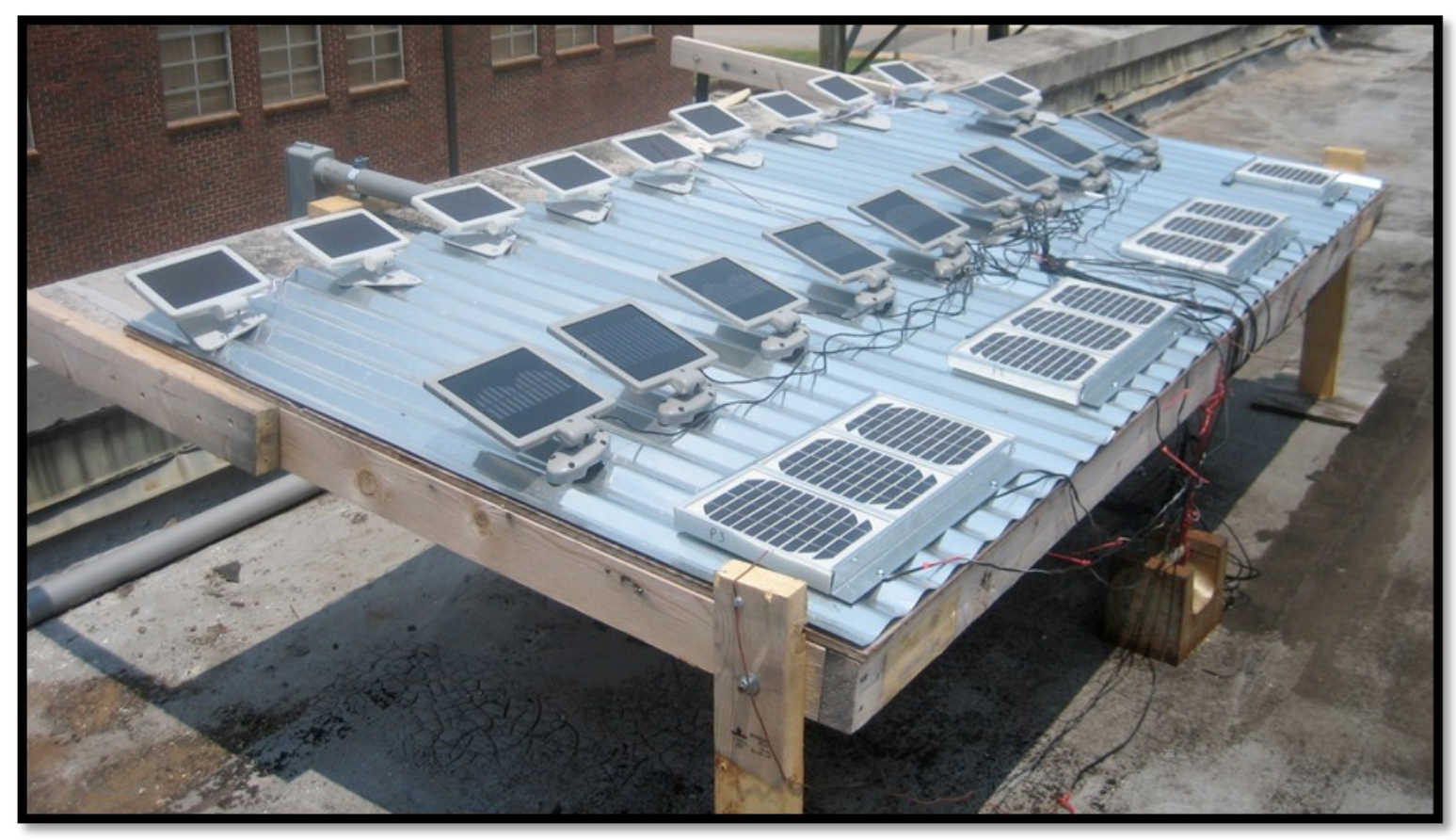

FIGURE 3

SOlar Panels installed on a Replica of a typical Peruvian roof.

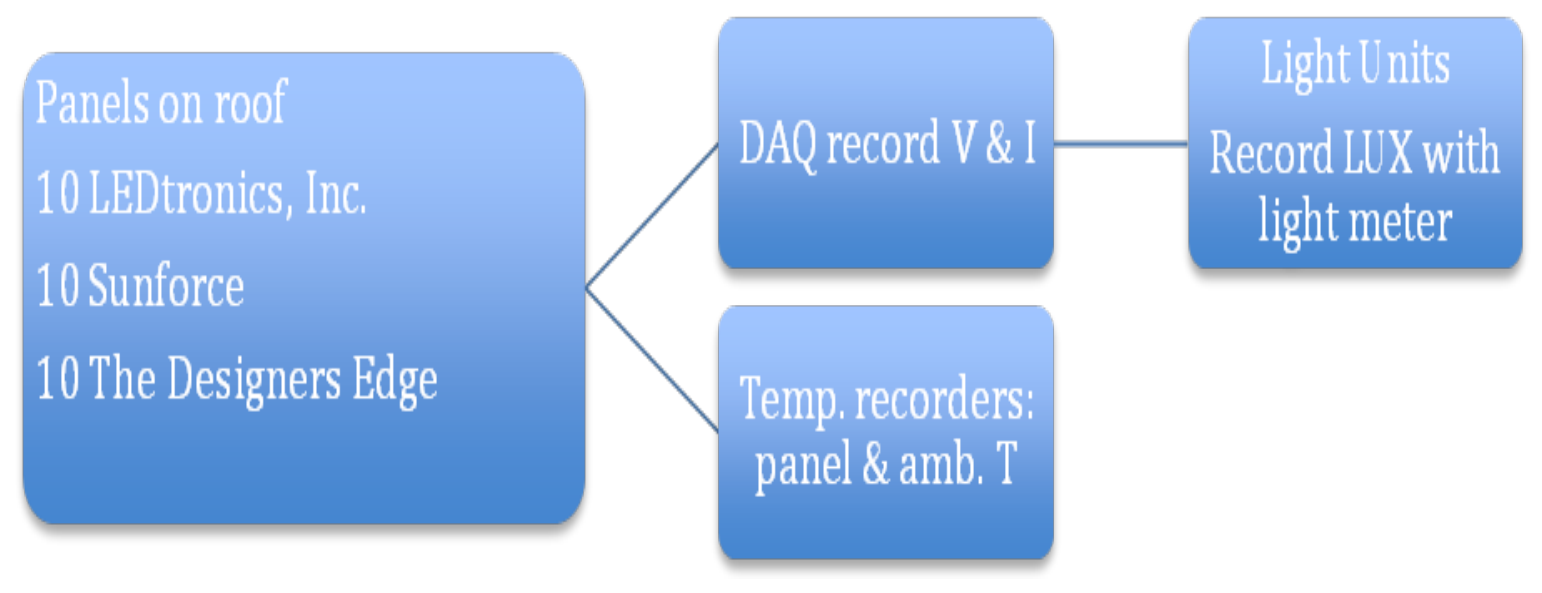

FIGURE 4

SChEMATIC DiAgRAM OF TESTING

\section{Systems Descriptions}

The three tested systems are as follows (summarized in Table I). The LEDtronics, Inc. Solar Camping Lantern system comes with a 7.875 inch X 5.875 inch solar panel, a 9.375 inch tall lantern with a 2.125 inch radius, an $\mathrm{AC} / \mathrm{DC}$ charger and a car charger. The panel charges the lantern through a 4.5-foot cable. The lantern has a total of 32 LED bulbs, whose brightness is 
controlled by an adjustable switch. The light output was measured at full power. Its packaging advertises that the lead-acid battery will power the lantern for 20 hours when it is fully charged. The system is packaged in an 11.5 inch X 6.25 inch X 5.875 inch box that weighs $2.2 \mathrm{lbs}$. The LEDtronics, Inc. Solar Camping Lantern cost approximately $\$ 50$ in the fall of 2008, making it the most expensive system.

The Sunforce Solar Shed Light is packaged with a 7-inch X 5.5 inch solar panel, an 8.625inch X 2.375 inch X 1.875 inch LED light and mounting screws. Attached to the solar panel is a flat triangular mount with 3 screw holes and an 8.1-foot cable used to power the rechargeable batteries in the light. The system's light has 5 LED bulbs that are larger than the bulbs in the other lights and can be turned on or off with a switch located on the side. A full charge of the nickel-cadmium batteries should provide at least 2 hours of illumination for its users. The system when packaged weighs $1.8 \mathrm{lbs}$ with dimensions of 11.125 inch X 8.75 inch X 5.875 inch. The Sunforce Solar Shed Light is the second most expensive system, costing approximately $\$ 35$ in the fall of 2008.

The Designers Edge Solar Shed Light system includes a 6.75-inch X 8 inch solar panel, a Ushaped mount, a 9.125-inch X 2.625 inch X 1.875 inch light and mounting screws. The panel charges the nickel-cadmium batteries in the light with a 16-foot cable. A pull string on the side turns the light on and off. The light has a switch on the side that determines whether 5 or 10 LED bulbs will be used. The 10 LED bulb setting was used for this experiment in order to measure the largest reading of LUX. When the batteries have been fully charged, the light is advertised to last at least 2 hours when using 10 bulbs. The system in its packaging weighs $2 \mathrm{lbs}$ with dimensions of 12 inch X 12 inch X 3 inches. It is the least expensive system only costing approximately $\$ 24$ with a 2-year warranty. Figure 5 shows the lights included in the systems. 


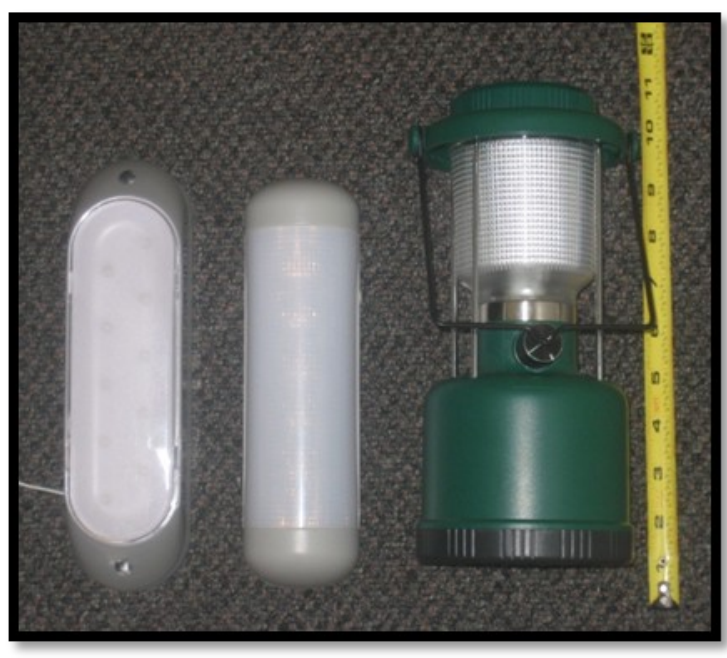

FIGURE 5

Systems' Lights: (1) The Designers Edge, (2) Sunforce, (3) LeDtronics, Inc.

TABLE I

SUMMARY OF SYTEM INFORMATION

\begin{tabular}{|c|c|c|c|}
\hline $\begin{array}{l}\text { General System } \\
\text { Information }\end{array}$ & LEDtronics, Inc. & $\underline{\text { Sunforce }}$ & The Designers Edge \\
\hline$\overline{\text { Panel Surface Area }}$ & $4 \overline{46.3 \mathrm{in}^{2}\left(298.7 \mathrm{~cm}^{2}\right)}$ & $38.5 \mathrm{in}^{2}\left(248.4 \mathrm{~cm}^{2}\right)$ & $54.0 \mathrm{in}^{2}\left(348.4 \mathrm{~cm}^{2}\right)$ \\
\hline Front Cover & Glass & Plastic & Plastic \\
\hline Light Dimensions & $93 / 8 "$ x $41 / 4 "$ x 4 1/4" & $85 / 8 " \times 23 / 8 " \times 17 / 8 "$ & $91 / 8 " \times 25 / 8 " \times 17 / 8 "$ \\
\hline $\begin{array}{l}\text { Total Cost (tax not } \\
\text { included) }\end{array}$ & $\$ 50.00$ & $\$ 35.00$ & $\$ 24.00$ \\
\hline Rated Power & 2.01 watts & 8 watts & $\mathrm{N} / \mathrm{A}$ \\
\hline $\begin{array}{l}\text { Advertised Illumination } \\
\text { Time/Full Charge (Hr) }\end{array}$ & 20 & 2 & 2 \\
\hline $\begin{array}{l}\text { Weight of Unit w/ } \\
\text { Packaging (lbs) }\end{array}$ & 2.2 & 1.8 & 2 \\
\hline $\begin{array}{l}\text { Volume of Unit w/ } \\
\text { Packaging }\end{array}$ & $111 / 2 " \times 61 / 4 " \times 57 / 8 "$ & $111 / 8$ " X $83 / 4 " \times 57 / 8 "$ & $12^{\prime \prime} \times 12^{\prime \prime}$ x $3 "$ \\
\hline Cable Length (ft) & 4.5 & 8.1 & 16 \\
\hline Number of LED Bulbs & 32 & 5 & 10 \\
\hline Country of Origin & Pakistan & China & China \\
\hline Battery Type & Lead Acid & $\mathrm{Ni}-\mathrm{Cd}$ & $\mathrm{Ni}-\mathrm{Cd}$ \\
\hline Warranty (year) & 1 & 1 & 2 \\
\hline
\end{tabular}




\section{Scoring and Weighing Criteria}

This study was split into 5 main categories: Panel Performance, Light Performance, On-Site Operation, Maintenance, and Sustainability and Environmental Impact. These categories were judged based on their performances and observations throughout the study. The weighting and scoring table shown in Table VII was developed to assist in evaluating the systems. The categories were assigned a weight with respect to their importance. Then this weight was divided up among the subcategories. The highest score a system could achieve was 100 points. The panel and light performances were quantitatively evaluated based on data collected during the study. Assessments in the other categories were based on the opinions and observations or the researcher. The results can be seen in Table III through Table VII in the Discussion section.

\section{Panel Performance}

\section{Results}

Voltage and current output of the systems are discussed in the following section. These outputs are averaged and graphed against time along with average panel temperature during clear, overcast, cloudy, and precipitation events. Figure 6 shows typical average voltage output from each system during clear conditions. This particular test occurred on September 4, 2009 from 7:20 AM to 12:00 PM. The LEDtronics Inc. panels have the best average producing over 10.00 volts throughout most this period. Sunforce always produces more than 6.00 volts and early in the run produces more than 7.00 volts. The Designers Edge panels have the worst voltage output, dipping below 6.00 volts. The Sunforce and Designers Edge panels seem to consistently show a slight decrease in voltage once the panel temperature gets close to $90^{\circ} \mathrm{F}$. At approximately 11:35 AM all of the panels show a sudden decrease in output that may indicate clouds moving overhead. Throughout the study the panels on average reacted this way during clear conditions.

On September 11, 2009 Tuscaloosa was overcast (approximately 100\% cloud cover) from 8:30 AM to 1:00PM. This day best reflects the typical behavior of the panels during overcast conditions. The average voltage outputs of the systems on that day can be seen in Figure 7. The average LEDtronics, Inc. panel voltage is relatively constant at its maximum value of 10.73 volts, with one short exception just after 10:30. The panel temperature also decreases at this point which may be due unusually heavy cloud cover. The Sunforce panel produces just below 7.00 volts during this time period, and The Designers Edge panel averages just over 6.00 volts. Overall, the voltage productions remain stable as the average panel temperature climbs over $90^{\circ} \mathrm{F}$. There was an outlier in the Sunforce total; one panel produced a minimum of 4.72 volts and was left out of Figure 7. 


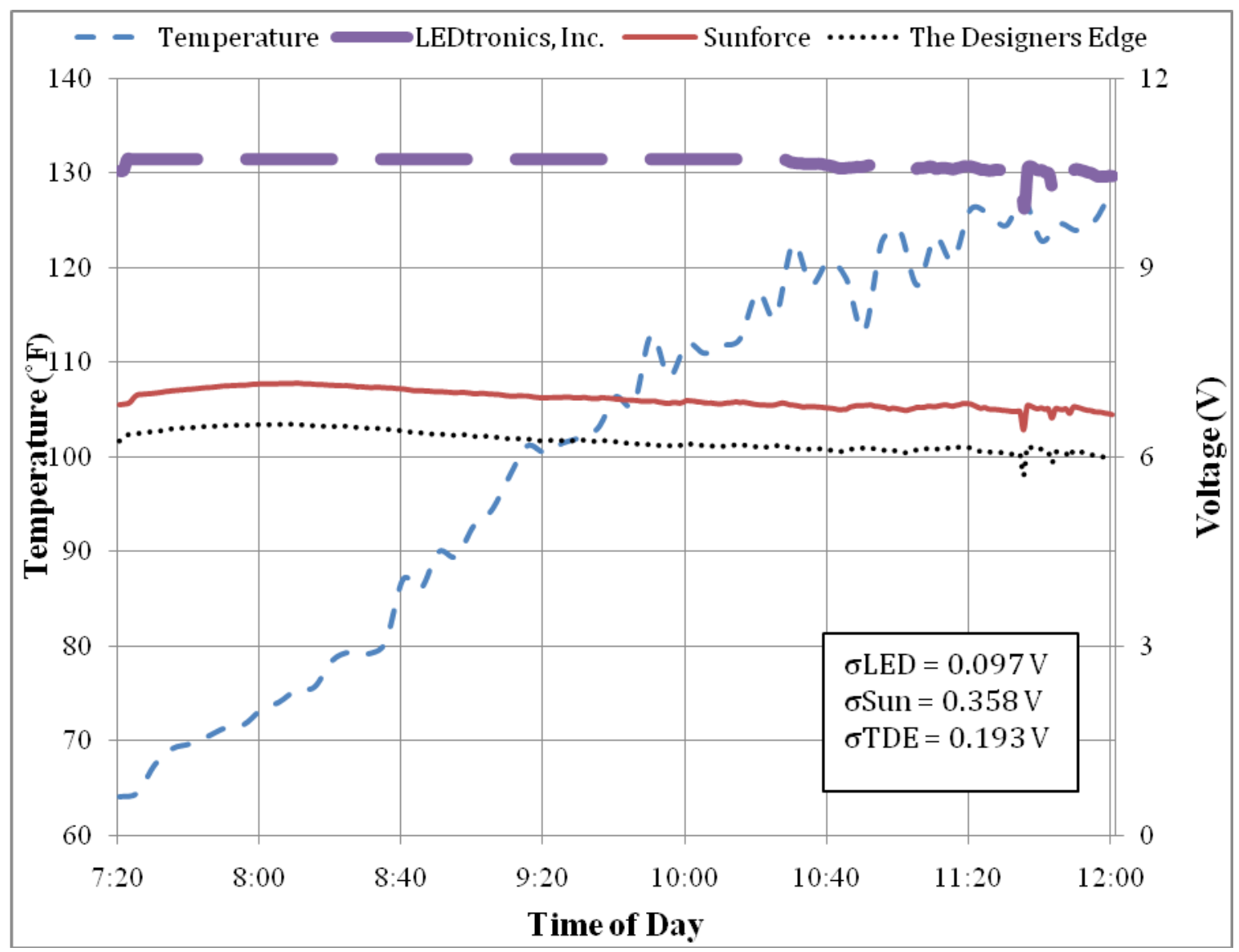

FIGURE 6

TyPicAl VOLTAGE OUTPUT AVERAGED OVER 4 PANELS DURING GENERALLY CLEAR CONDITIONS (9/4/2009 7:20 AM-12:00 PM, Maximum Ambient Temperature 88F). 


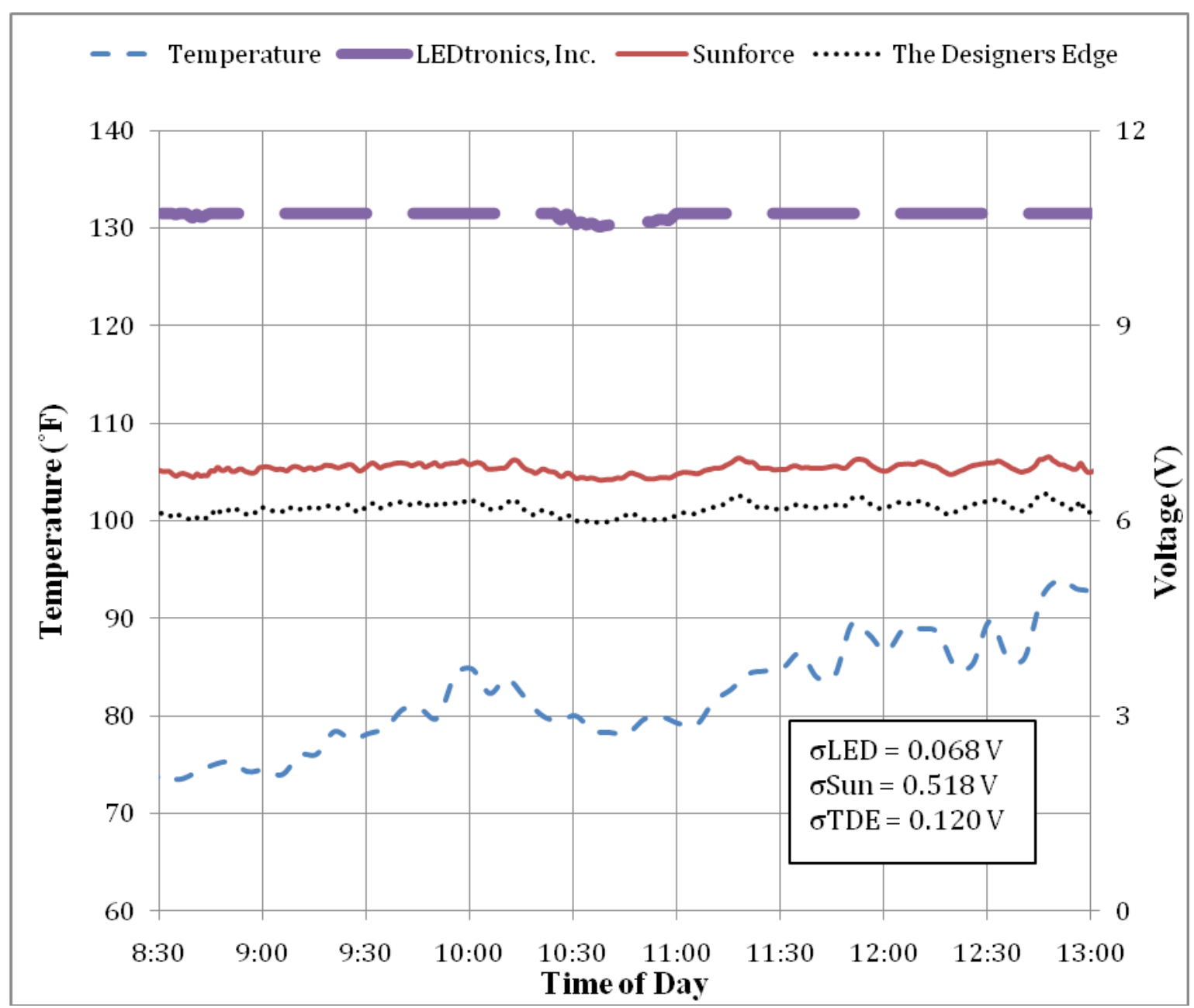

FIGURE 7

TyPicAl VOlTAGE OUTPUT AVERAGED OVER 4 PANELS DURING OVERCAST CONDITIONS (9/11/2009 8:30 AM1:00 PM, Maximum Ambient TEMPERATURE 80%).

Figure 8 shows the average panel outputs for each system during cloudy conditions (over 70\% cloud cover) on September 18, 2009 from 10:00 AM to 5:00 PM. This time period reflects the typical behavior of the panels during this type of condition. Once again the LEDtronics, Inc. panel produces the most voltage, regularly generating more than 10.00 volts. The Sunforce panel generates between 6.00 and 7.00 volts. The Designers Edge panels average between 5.50 and 6.75 volts. With lower panel temperatures, the panels did not appear to show increased voltage production. 


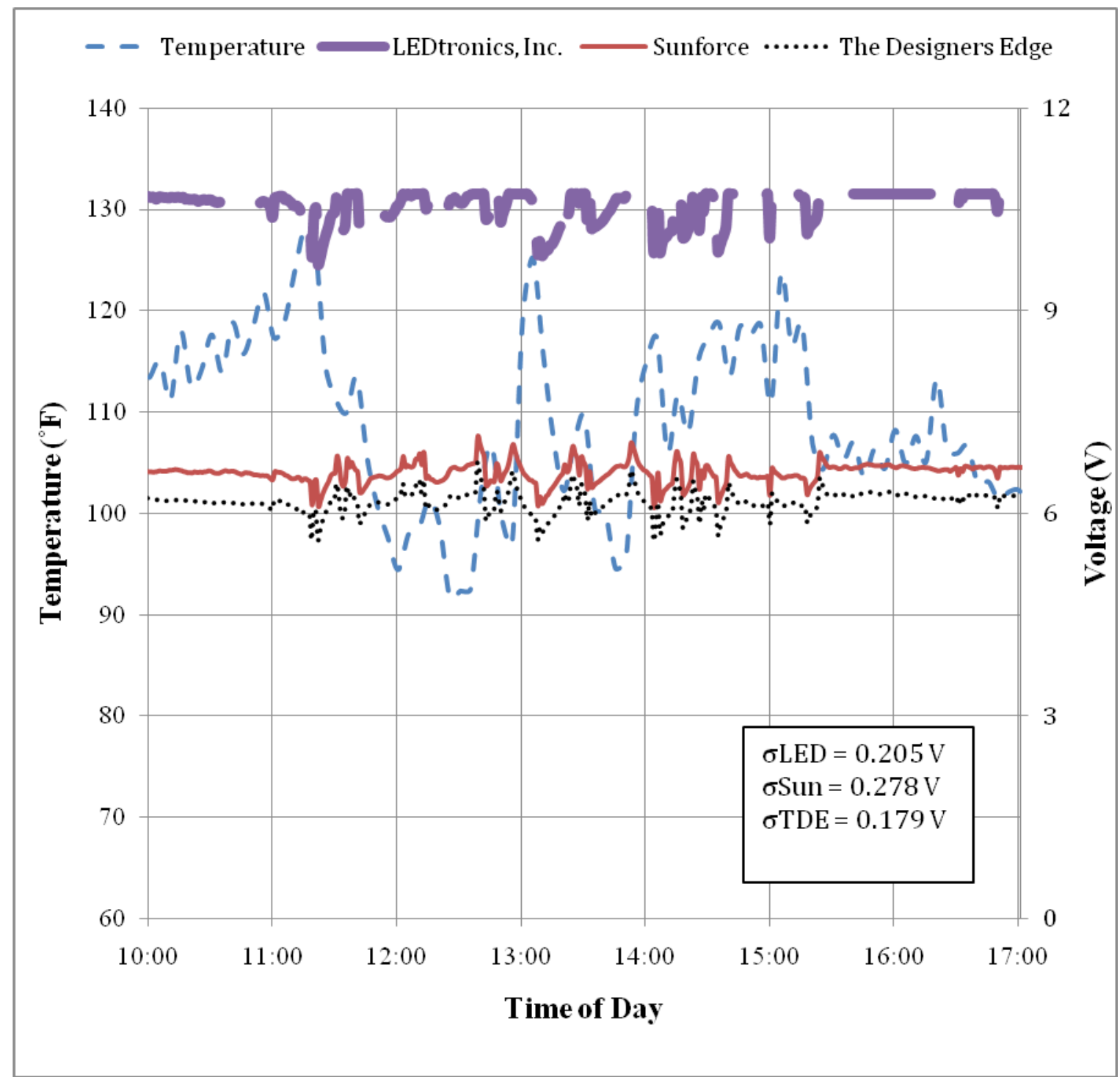

FIGURE 8

Typical VOltage outPut AVERAged OVER 4 PANels DURing Cloudy CONDITIONS (9/8/2009 10:00 AM5:00 PM, Maximum Ambient Temperature $\left.86^{\circ} \mathrm{F}\right)$.

Figure 9 displays the average voltage output during a precipitation event on September 14, 2009 between 1:30 PM to 4:00 PM. This day also shows how the panels typically react to such conditions. This is where the panels generate the least amount of voltage. Through the majority of this run the LEDtronics, Inc. panel averages between 7.80 and 8.70 volts. The Sunforce panel produces approximately 5.50 volts. The Designers Edge was only able to generate between 4.90 and 5.20 volts. The Tuscaloosa Airport reported 0.67 inches of rain during this short period during which the panels' productions fell $76.32 \%$ below their maximum outputs during optimal conditions (clear and overcast) [5]. It is worth noting that again one Sunforce panel did not perform as well as the other three panels. This panel only produced 1.12 volts when all of voltage outputs were at their lows. It was left out of Figure 9. 


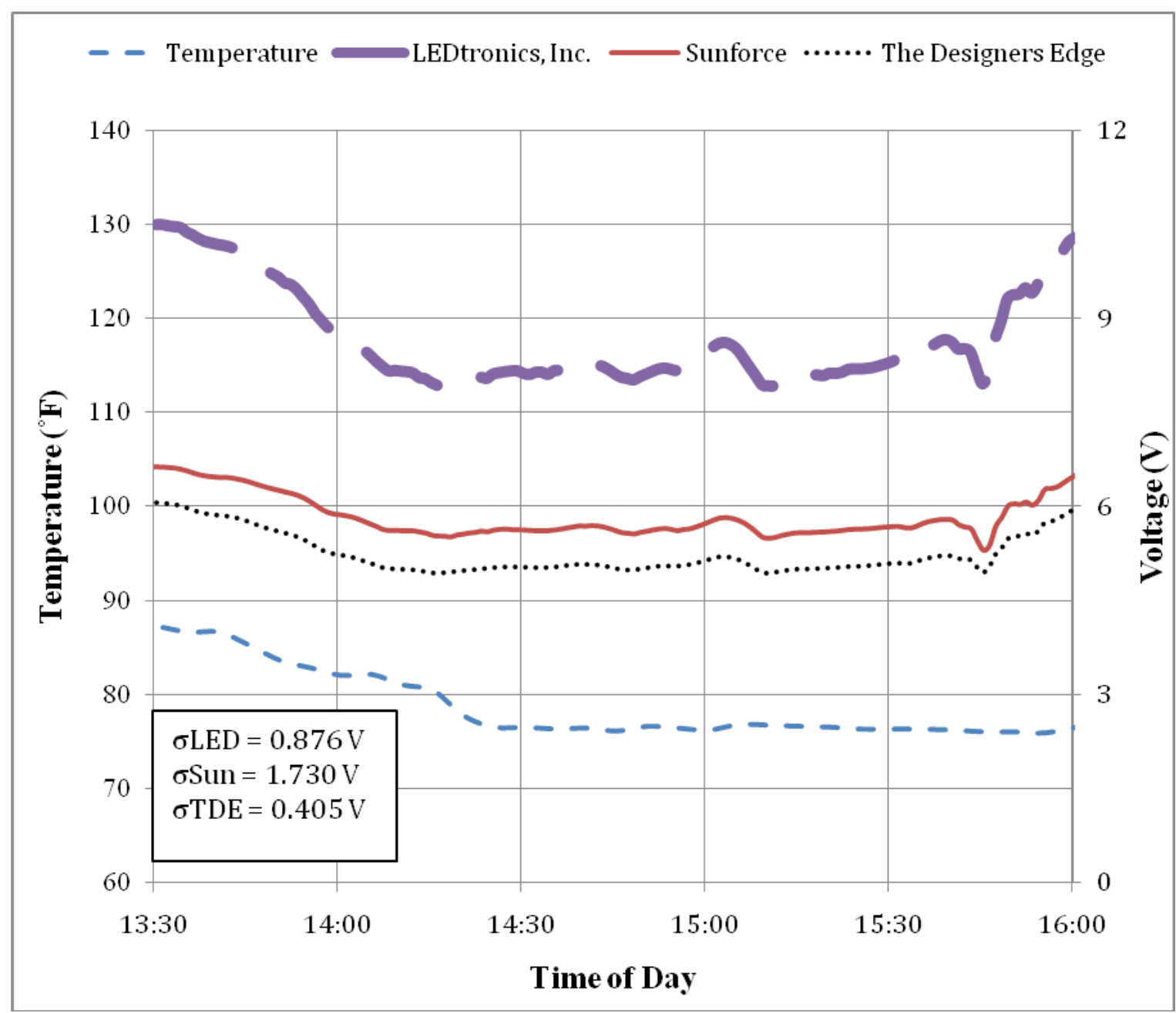

FIGURE 9

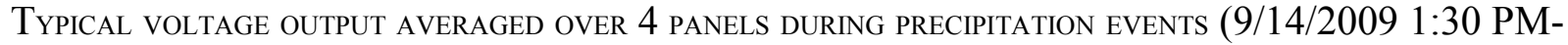
4:00 PM Maximum Ambient Temperature $85^{\circ} \mathrm{F}$ ).

During the clear conditions that occurred on September 4, 2009 as seen in Figure 10, the current outputs for all three systems maintain their maximum output of $21.38 \mathrm{~mA}$ throughout the majority of the time period. The Sunforce and LEDtronics, Inc. panels rose to the maximum production before the Designers Edge panel. The panels typically behaved this way during clear conditions. With panel temperatures rising and the current values remaining stable, it appears that there is no loss in current production due to temperature. 


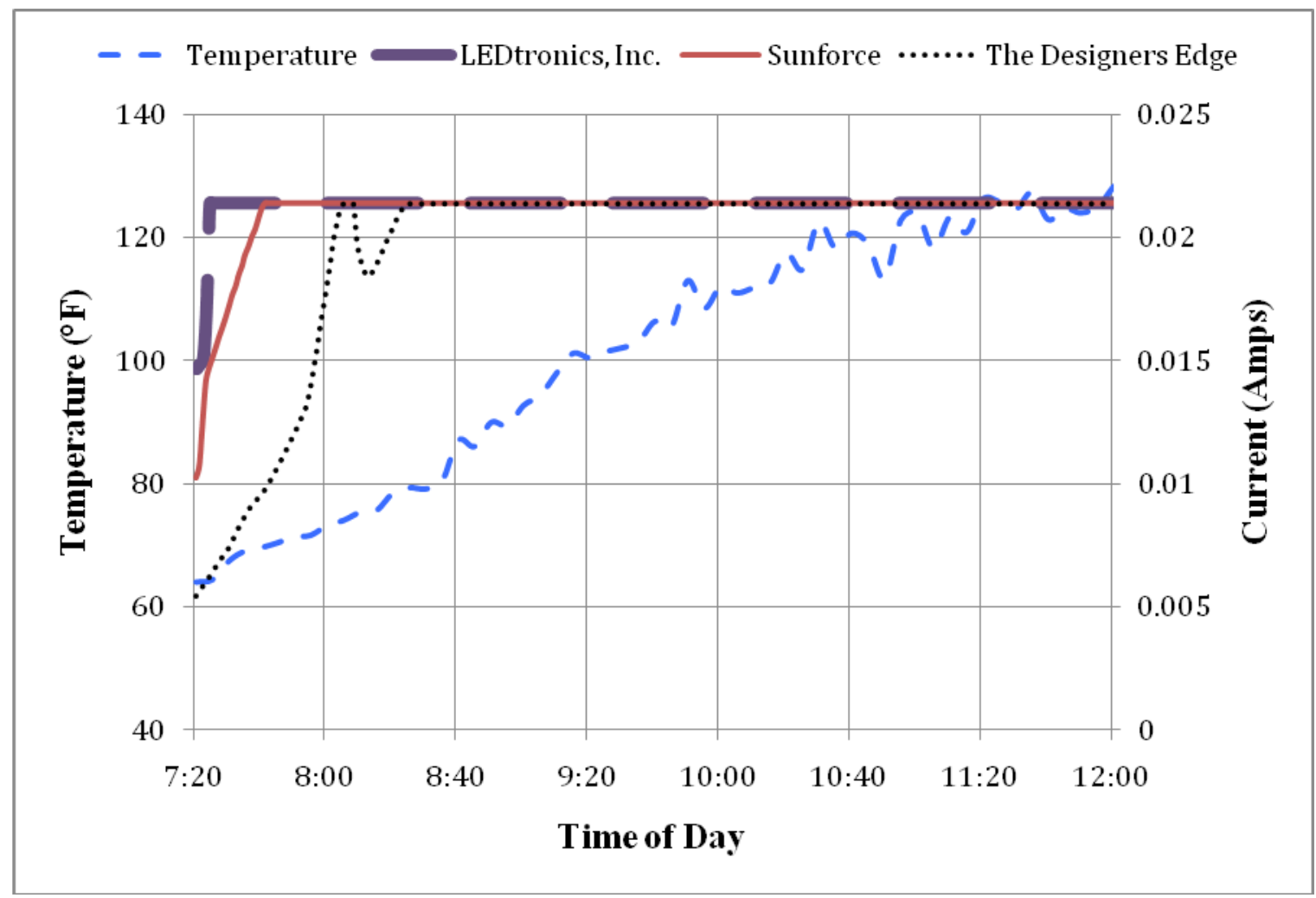

FIGURE 10

Typical CURRENT OUtPut AVERAGEd OVER 4 PANELS DURING GENERALLy CLEAR CONDITIONS (9/4/2009 7:20 AM-12:00 PM, Maximum Ambient Temperature $88^{\circ} \mathrm{F}$ )

Figure 11 displays the typical current output during the overcast conditions that took place on September 11, 2009. The Designers Edge panel appears to be the most affected. Unlike the others, it cannot establish a constant current output for more than 30 minutes. Throughout this run, the LEDtronics, Inc. panel maintains a steady maximum output of $21.38 \mathrm{~mA}$. The Sunforce panel also produces this amount, but does stagger when possible heavy cloud cover exists. Once again, it looks as if panel temperature does not affect the current outputs of the panels. 


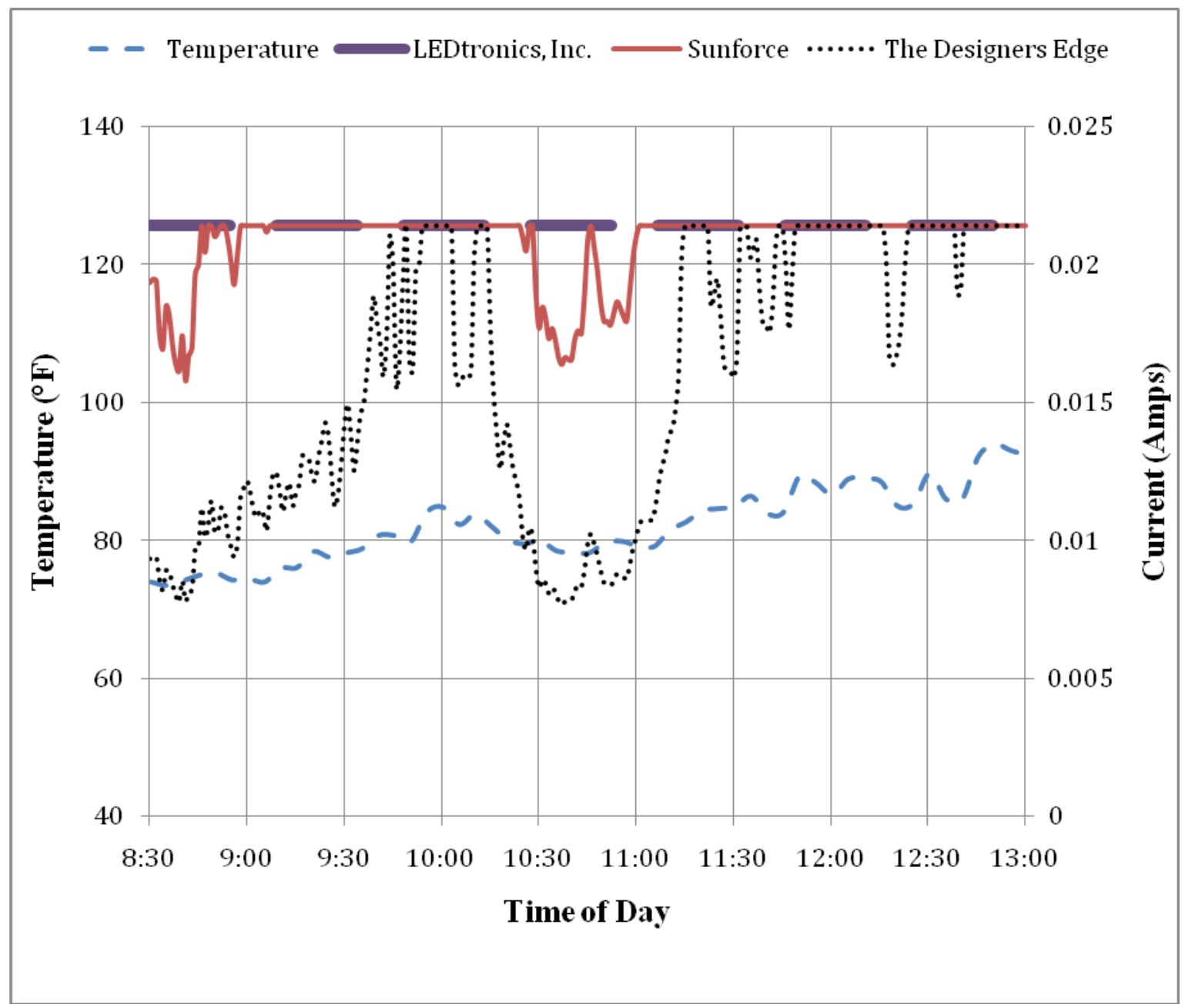

FIGURE 11

TYPiCAL CURRENT OUTPUT AVERAGED OVER 4 PANELS DURING OVERCAST CONDITIONS (9/11/2009 8:30 AM1:00 PM, Maximum Ambient Temperature $80^{\circ} \mathrm{F}$ ).

In Figure 12 are the current outputs from the cloudy conditions on the $8^{\text {th }}$ of September of 2009. The Sunforce and LEDtronics, Inc. panels are able to maintain their maximum values throughout the time period. The Designers Edge panel fluctuates between 12.24 and $21.38 \mathrm{~mA}$. It is apparent that there may have been heavier cloud cover during this time. However, this cloud cover did not affect the other panels, nor did panel temperature. 


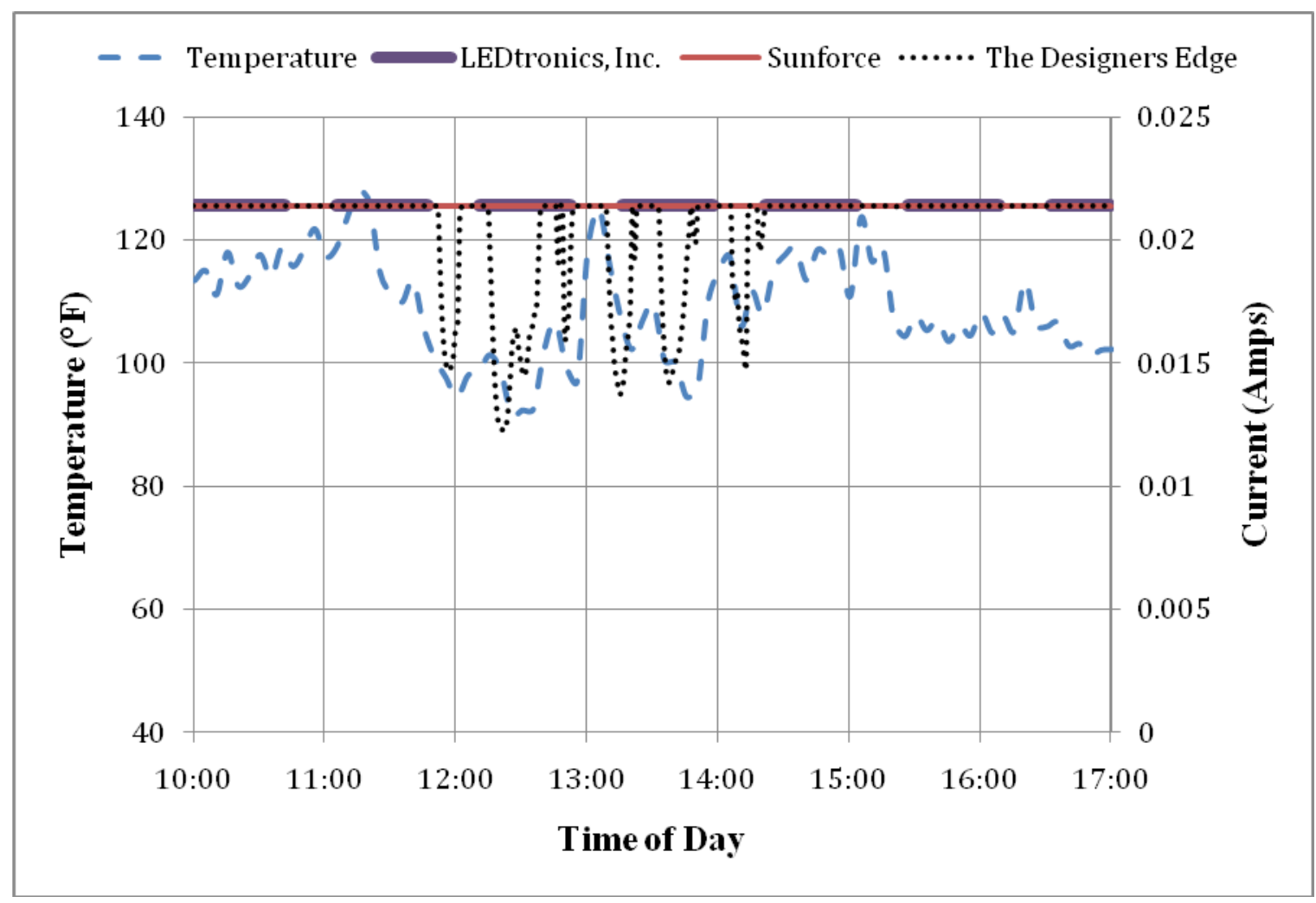

FIGURE 12

Typical Current outPut AVERAged over 4 Panels during Cloudy Conditions (9/8/2009 10:00 AM5:00 PM, Maximum Ambient Temperature $\left.86^{\circ} \mathrm{F}\right)$.

Figure 13 shows how current output reacts to a precipitation event on September 14, 2009 and in general. Overall, this is where the panels are at their worst. They do continue to follow the trend they have experienced throughout the experiment with the LEDtronics, Inc. panel producing the most current, The Designers Edge panel with the worst output, and the Sunforce panel in between the two. The Designers Edge panel hardly produces any current during the majority of this run. The other two stay below $5.00 \mathrm{~mA}$ during the storm's heaviest rainfall.

Table II displays the range of power the panels produce during varying conditions. The average best and worst voltages were paired with their corresponding currents. Overall, the LEDtronics, Inc. panel produces the most power with the Sunforce panel following with the second most, and The Designers Edge panel producing the least amount of power. 


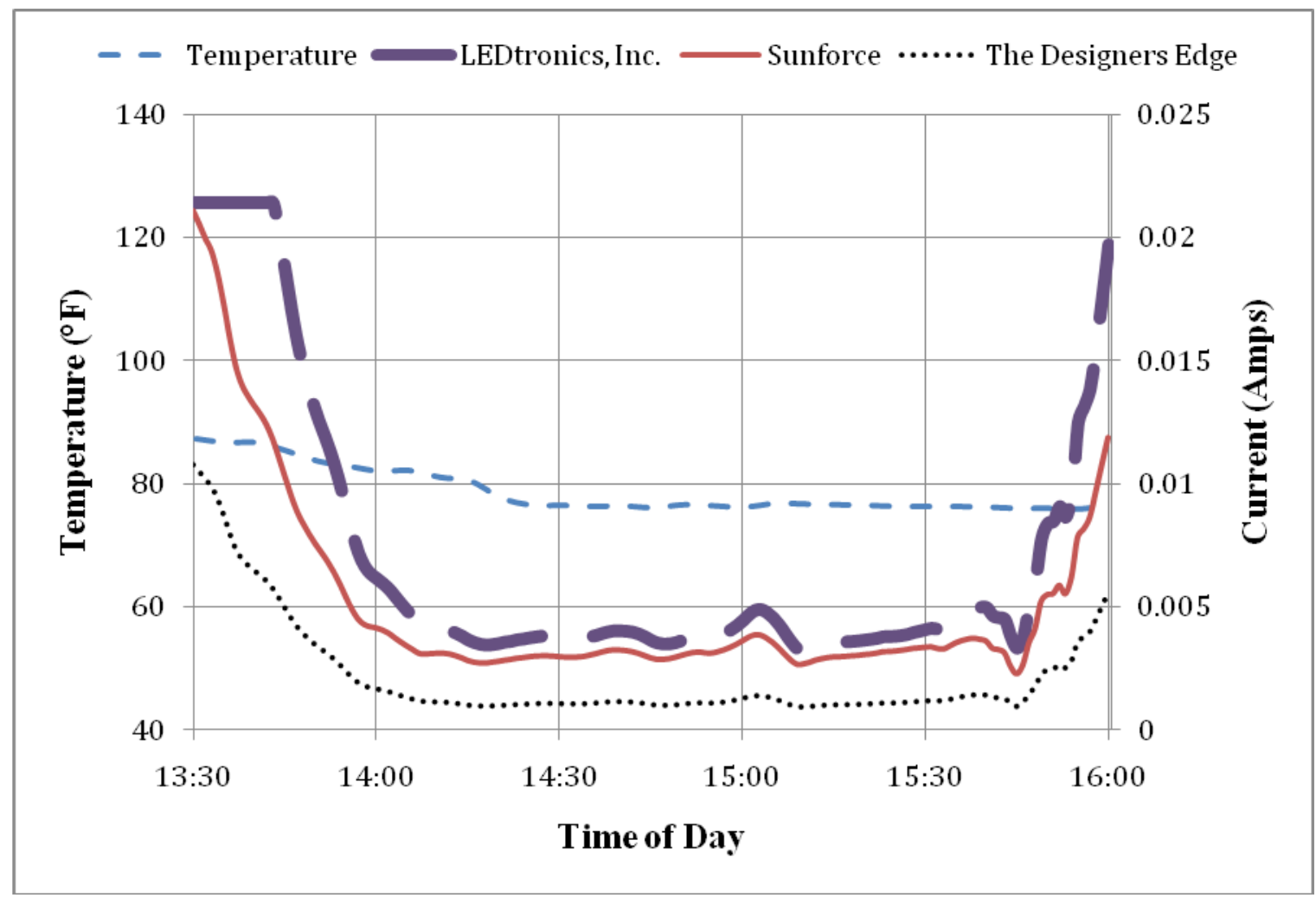

FIGURE 13

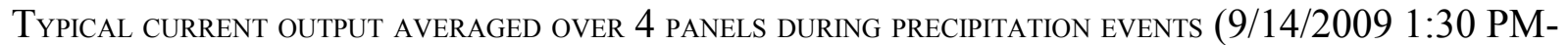
4:00 PM, Maximum Ambient Temperature $85^{\circ} \mathrm{F}$ )

TABLE II

POWER RANGES OF PANELS (WATTS) DURING SPECIFIED CONDITIONS

\begin{tabular}{ccccc}
\hline System & Clear & Overcast & Cloudy & Precipitation \\
\hline $\begin{array}{c}\text { LEDtronics, } \\
\text { Inc. }\end{array}$ & $0.212-0.229 \mathrm{~W}$ & $0.225-0.229 \mathrm{~W}$ & $0.212-0.229 \mathrm{~W}$ & $0.026-0.200 \mathrm{~W}$ \\
Sunforce & $0.137-0.153 \mathrm{~W}$ & $0.108-0.149 \mathrm{~W}$ & $0.130-0.152 \mathrm{~W}$ & $0.012-0.067 \mathrm{~W}$ \\
$\begin{array}{c}\text { The Designers } \\
\text { Edge }\end{array}$ & $0.122-0.139 \mathrm{~W}$ & $0.046-0.137 \mathrm{~W}$ & $0.117-0.143 \mathrm{~W}$ & $0.011-0.061 \mathrm{~W}$ \\
\hline
\end{tabular}

\section{Light Performance}

Figure 14 displays the lights' average outputs during short-term readings, over the first seven uses of the lights. These runs last only 90 minutes. The LEDtronics, Inc. lanterns generate some very high readings, but four of the lanterns did not work. The Sunforce lights are probably the most consistent units in that they do not produce readings as varied as the other two systems. The Designers Edge lights produce some of the highest LUX readings throughout testing. Figure 15 offers a more comparative chart of the distribution of the light produced during short-term testing. A1-A10 are Sunforce units, B1-B10 are The Designers Edge units, and C1-C10 are LEDtronics, Inc. units. 
International Journal for Service Learning in Engineering

Vol. 5, No. 1, pp. 64-93, Spring 2010

ISSN 1555-9033

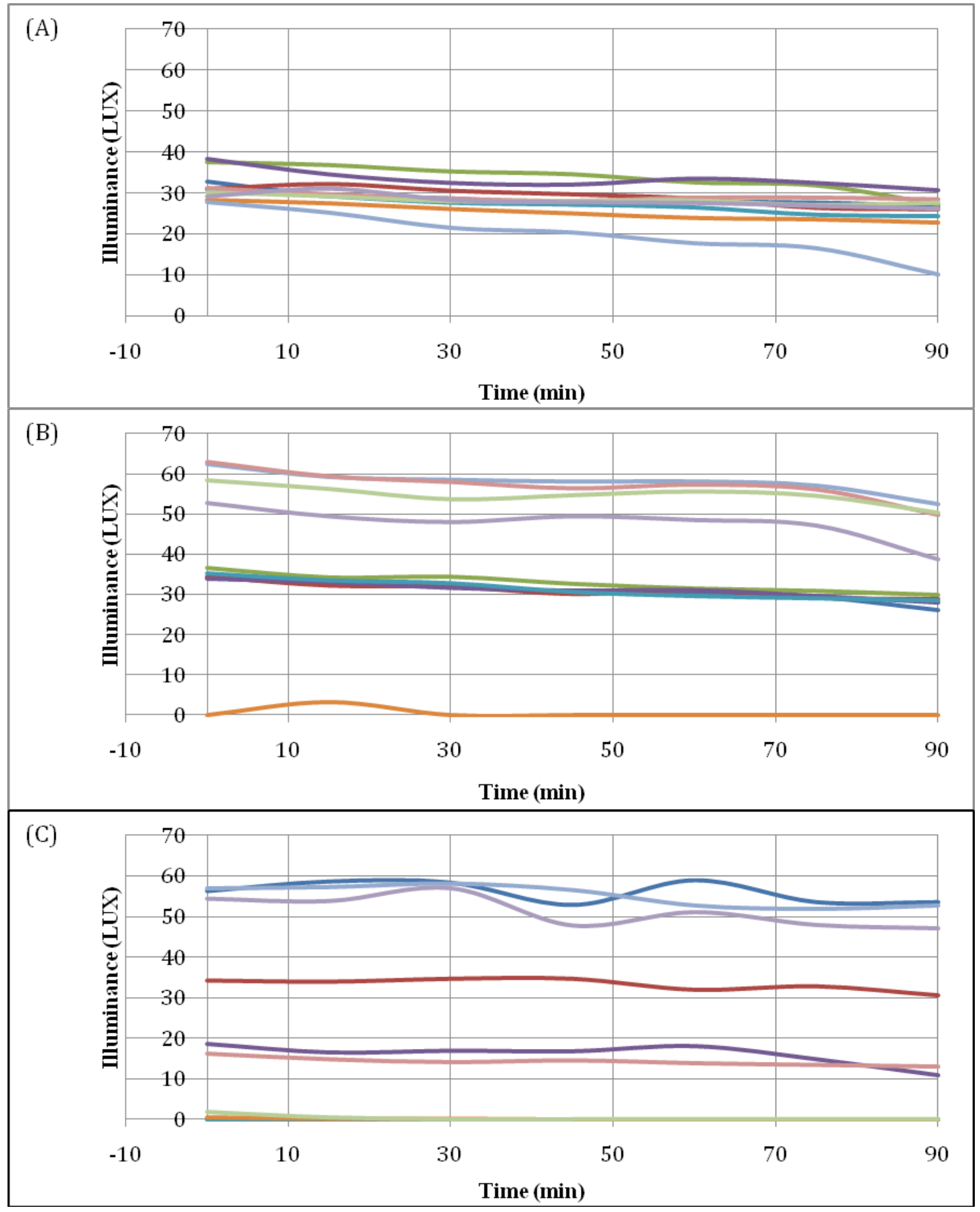

FIGURE 14

Short-term readings of lights (A) Sunforce, (B) The Designers Edge, (C) LEDtronics, Inc. 


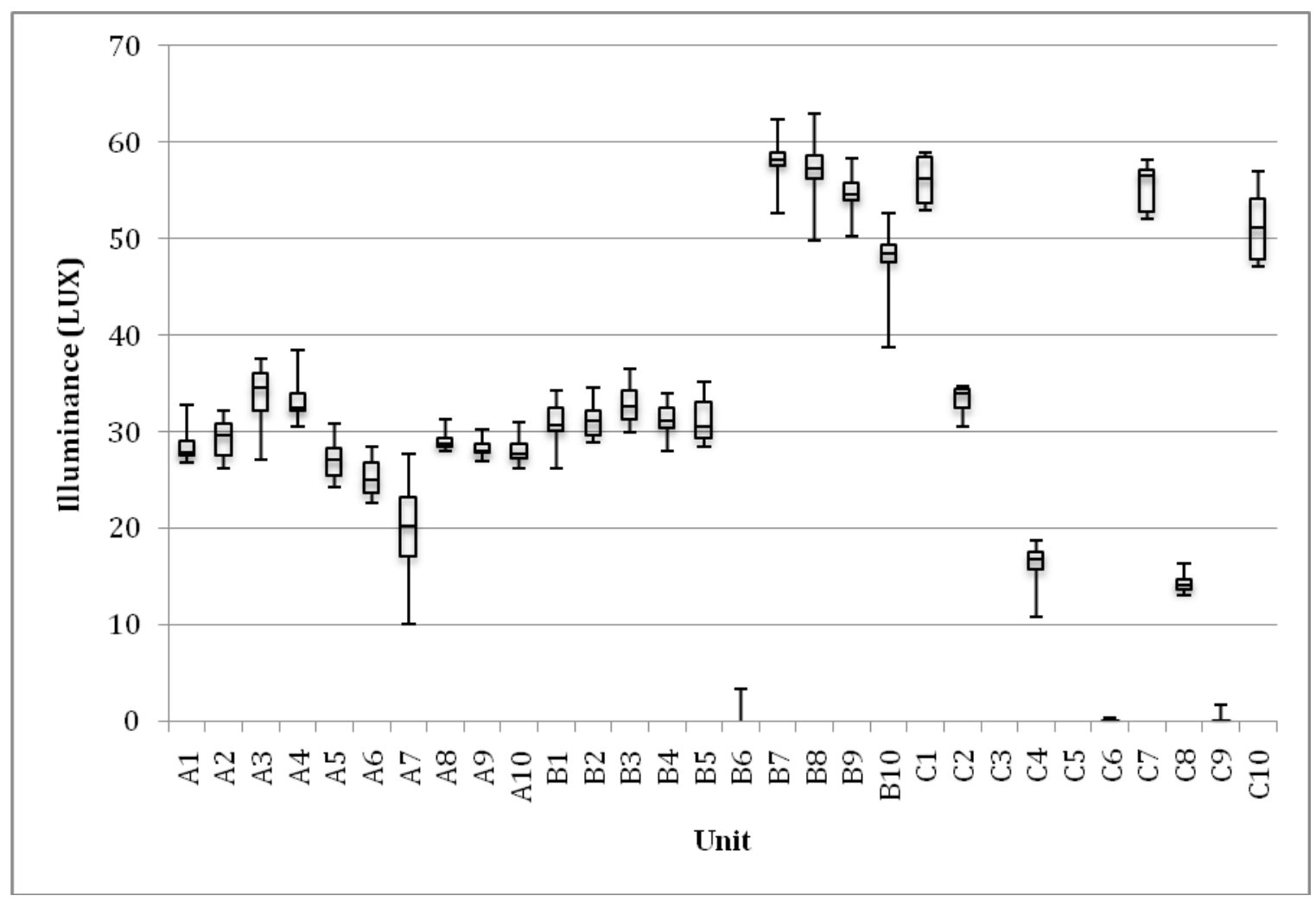

FIGURE 15

Box plot of Short-term readings of lights (A) Sunforce, (B) The Designers Edge, (C)

LEDTRONICS, INC.

Figure 16 displays the long-term readings of the lights. Long-term readings are the cumulative averages of all of the readings from all of the lights. These tests run until the lights quit producing or up to 240 minutes, whichever comes first. The LEDtronics, Inc. lanterns split into four groups of outputs and they seem to start producing less light after 120 minutes. Once again, there are four lanterns that do not work. The Sunforce lights for the most part stay consistent in their light generation. The majority of the lights seem to rapidly decrease after 150 minutes. The Designers Edge lights break into two groups that begin to reduce light production after 150 minutes. One light does not work. Like Figure 15, Figure 17 offers a more comparative chart of the light output generated by these light units. It appears from the data that the light productions were not significantly affected by unfavorable atmospheric conditions like cloudy conditions or precipitation events. 

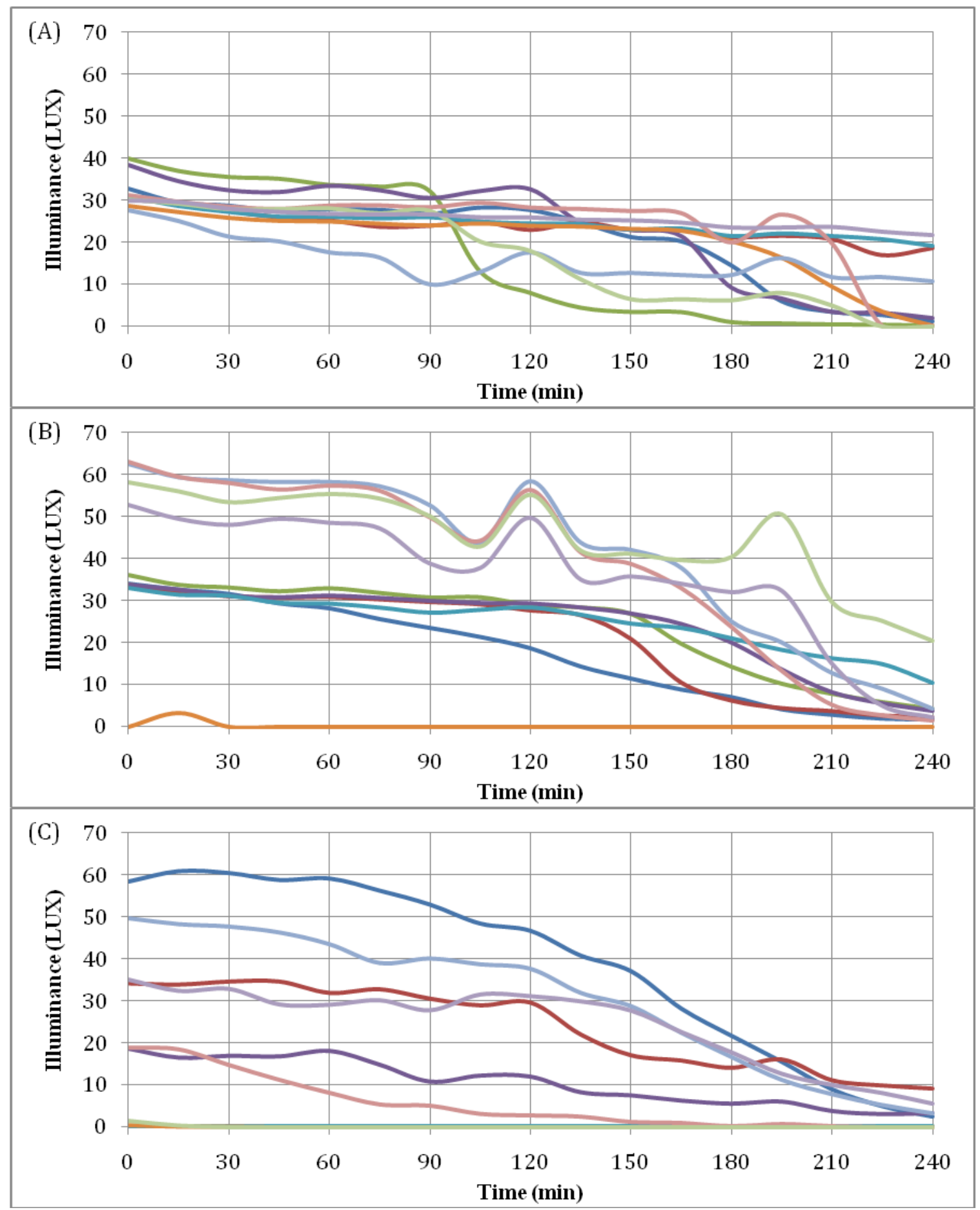

FIGURE 16

Long-term readings of lights (A) LEDtronics, Inc. , (B) Sunforce, (C) The Designers Edge 


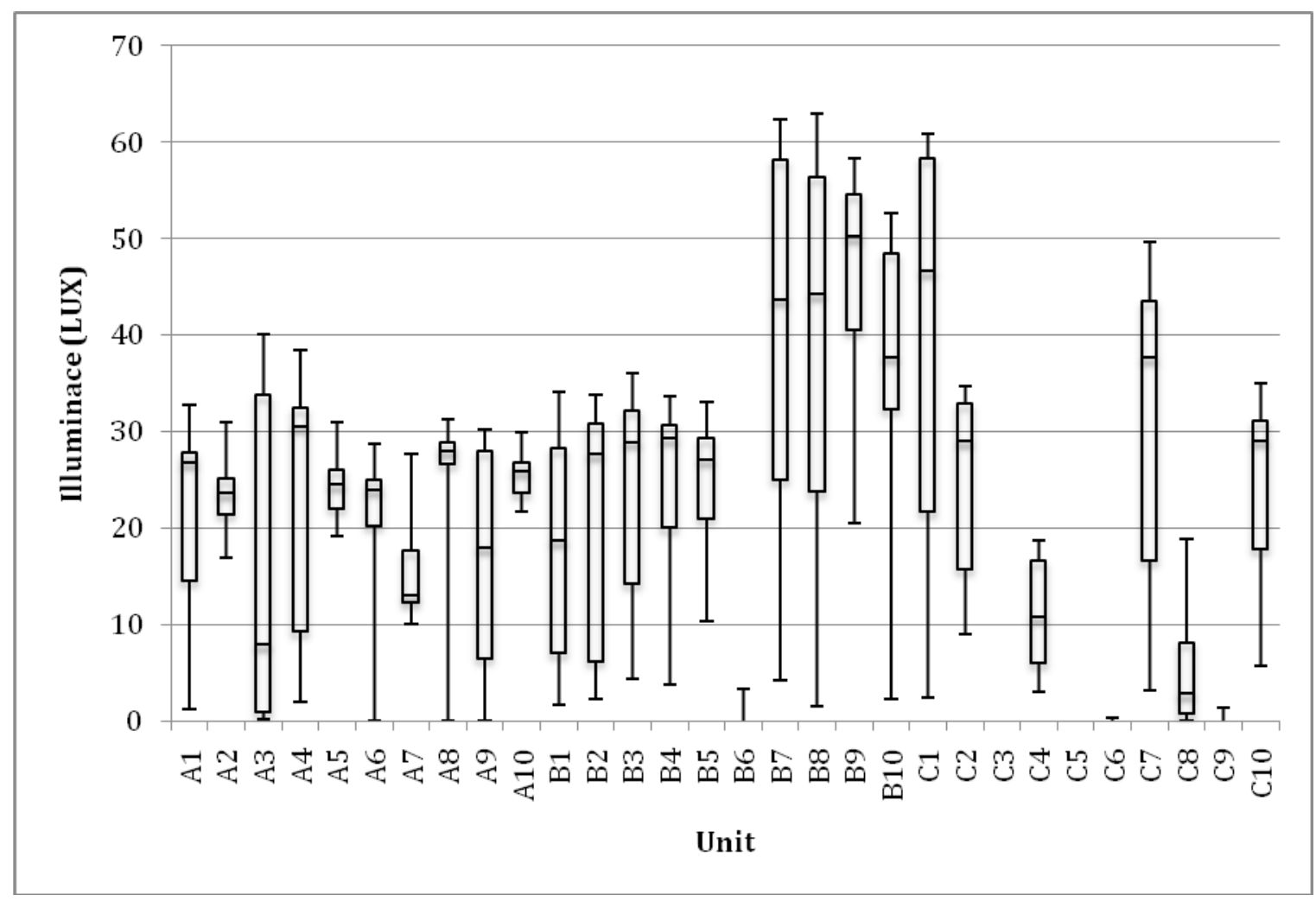

FIGURE 17 Box plot of Long-term readings of lights (A) Sunforce, (B) The Designers Edge, (C) LEDtronics,
Inc.

\section{Discussion}

The overall performance of the systems was evaluated using weighting and scoring ${ }^{7}$. This technique does not necessarily determine the "best" alternative, but it does produce a transparent evaluation that can be used as a basis for further discussion as more information becomes available. First the main evaluation criteria were selected, and a relative importance or weight was assigned to each. The main criteria are as follows: 1. panel performance $(30 \%), 2$. light performance $(30 \%), 3$. onsite operation and maintenance $(30 \%)$ and 4 . sustainability and environmental impact (10\%). Note that the weights of the four main criteria sum to $100 \%$. Each of these main criteria was further subdivided as necessary. For example panel performance was subdivided into output $(20 \%)$ and $\$ /$ Watt $(10 \%)$. The weights for these sub criteria sum to the weight of the main criteria. And output was further subdivided into output under clear, overcast, cloudy and percipitation conditions ( $4 \%$ each). In each subcategory performance was scored on a scale of 1 to 100 , then the subcategory scores multiplied by a the weighting factor were summed to determine the total score. A perfect system would score a total of 100 points. Where test data was not available experience-based judgement and observations of the systems' performances in these areas were used to evalute the systems' behaviors.

\section{Ratings of Panel Performance}


Panel performance accounted for $30 \%$ of the overall score, $20 \%$ for power output and $10 \%$ for cost per watt of power. Overall, the LEDtronics, Inc. panels have the highest average outputs during all four atmospheric conditions. As seen in Table II, these panels' power ranges are always greater than the other two systems' panels. The Sunforce panels and The Designers Edge panels' power productions are very close to one another; however, the Sunforce panels generate slightly more power during all the weather conditions. One Sunforce panel did perform poorly throughout monitoring, and it was at its worst during overcast conditions and precipitation events. Unfortunately, only four panels of each system were tested, so it is difficult to determine whether or not this is common in the Sunforce panels. Each panel was scored on a scale of 1100 for each weather condition. Then the scores were totaled for each system and averaged for overall performance as seen on Table III. Next, the panels were scored on a 1-100 scale according to their initial capital cost per peak power output over a two hour period. During peak hours, The Designers Edge panels' production (\$1.67 per Watt) costs less than the LEDtronics, Inc. LEDtronics, Inc. panels cost \$1.80 per Watt and Sunforce panels cost \$2.22 per Watt.

TABLE III

Panel Performance Ratings

\begin{tabular}{|c|c|c|c|c|c|}
\hline & $\frac{\text { Contribution to }}{\text { Total (\%) }}$ & $\frac{\text { Weight }}{(\%)}$ & $\frac{\text { LEDtronics, }}{\text { Inc. }}$ & Sunforce & $\frac{\text { The Designer's }}{\text { Edge }}$ \\
\hline Panel Performance & \multirow{7}{*}{30} & \multirow[b]{6}{*}{20} & & & \\
\hline Clear Conditions & & & 100 & 75 & 70 \\
\hline Overcast Conditions & & & 100 & 75 & 65 \\
\hline Cloudy Conditions & & & 100 & 90 & 80 \\
\hline Precipitation Event & & & 80 & 50 & 60 \\
\hline $\begin{array}{l}\text { Average Overall Panel } \\
\text { Performance }\end{array}$ & & & 95 & 72.5 & 68.75 \\
\hline $\begin{array}{l}\$ / \text { Watt (Peak } 2 \text { Hour } \\
\text { Period) }\end{array}$ & & 10 & 66 & 33 & 100 \\
\hline Subtotal & & & 25.60 & 17.80 & 23.75 \\
\hline
\end{tabular}

Rating of Lights' Performances

Light output accounted for $30 \%$ of the total score, further subdivided into $15 \%$ for failure rate, $4.5 \%$ for consistency of output, and $10.5 \%$ for overall light production. Fully forty percent of the LEDtronics, Inc. systems, failed to produce an adequate amount of light. Of the Designers Edge systems, only one light failed, while none of the Sunforce sytems failed. Since failure was a major factor in deciding which systems were or were not appropriate for future use, the weighting penalty was heavy. Next, do the lights from an individual manufacturer produce the same amount of light throughout their lives or do the lights degrade with time or vary from light to light? The LEDtronics, Inc. lights fell into 4 groups, and were seen as very inconsistent. The Sunforce lamps tended to generate a more consistent output of lighting. Excluding a few outliers, these lights seemed to yield values that were very close to one another. The Designers Edge lamps had two major groups, excluding the one lamp that produced very little light. One group had a larger output between 1.5 and 63 LUX. With regards to the overall production, it appears from the test data that a collection of The Designers Edge lamps produced the most illuminance. The Sunforce lights are second because of their ability to perform consistently and 
the LEDtronics lights place last because of their failure rate. The lamps will be assigned a score of up to 10.5 points based on their overall performance. The ratings are displayed on Table IV.

TABLE IV

LIGHT PERFORMANCE RATINGS

\begin{tabular}{|c|c|c|c|c|c|}
\hline & $\begin{array}{c}\text { Contribution to } \\
\text { Total (\%) } \\
\end{array}$ & Weight (\%) & $\frac{\text { LEDtronics, }_{\text {, }}}{\text { Inc. }}$ & $\underline{\text { Sunforce }}$ & $\begin{array}{c}\text { The Designer's } \\
\text { Edge }\end{array}$ \\
\hline Light Performance & \multirow[t]{4}{*}{30} & & & & \\
\hline Unit Failure Rate & & 15 & 60 & 100 & 90 \\
\hline $\begin{array}{l}\text { Consistency of } \\
\text { Systems' Lights }\end{array}$ & & 4.5 & 33 & 100 & 66 \\
\hline Overall Production & & 10.5 & 57 & 86 & 100 \\
\hline Subtotal & & & 16.47 & 28.53 & 26.97 \\
\hline
\end{tabular}

\section{On-Site Operation and Maintenance}

Operation and maintenance accounted for $30 \%$ of the final score, weighted equally between operation and maintenance. The subcategories that will be discussed in this section will be assigned weights between $1 \%$ and $4 \%$ with respect to their importance. Table V shows the ease of installation. More than likely, there will be no access to electic drills, so it is very important to know what type of equipment one will need to install these panels and lights. The Designers Edge and Sunforce lights are effortless to install, because of their predrilled screw holes. Their panels are also very simple to install and the systems come with the necessary screws for installation. They can be easily mounted with a phillips head screw driver. There is no installation planned for the LEDtronics, Inc. lantern. It was designed to be portable. That makes its panels more difficult to install in that they have no predrilled screw holes, and there is nowhere on the panel to drill any holes. When in Peru, the team found itself nailing these panels onto a wooden block, using the lip of the nailheads to hold the panels, and then hammering that block onto the roof. For this experiment, metal brackets were fitted to the panels to ensure a secure fitting.

All three of these systems are very simple to use. Once the panels have been installed, there is little interaction between them and the user unless the panels happen to fall off of the roof or need to be moved. All of the lights are very straightforward in operation. They all have an on/off switch and two of the lights' outputs can be adjusted. Mobility is considered to be another important feature. The LEDtronics, Inc lantern was designed to be portable. It has a carrying handle and it can shine its light in all directions. The other two lights were not meant to be portable, because they have predrilled screwholes. However, one can slide the Sunforce lights off of their screws. Two of the systems have adjustable angles and the majority of these panels keep their angle, except for two Sunforce panels as seen in Figure 18. It is very difficult to say why they did not maintain their angles. Birds may have altered them or it could be attributed weak connections from poor manufacturing. 


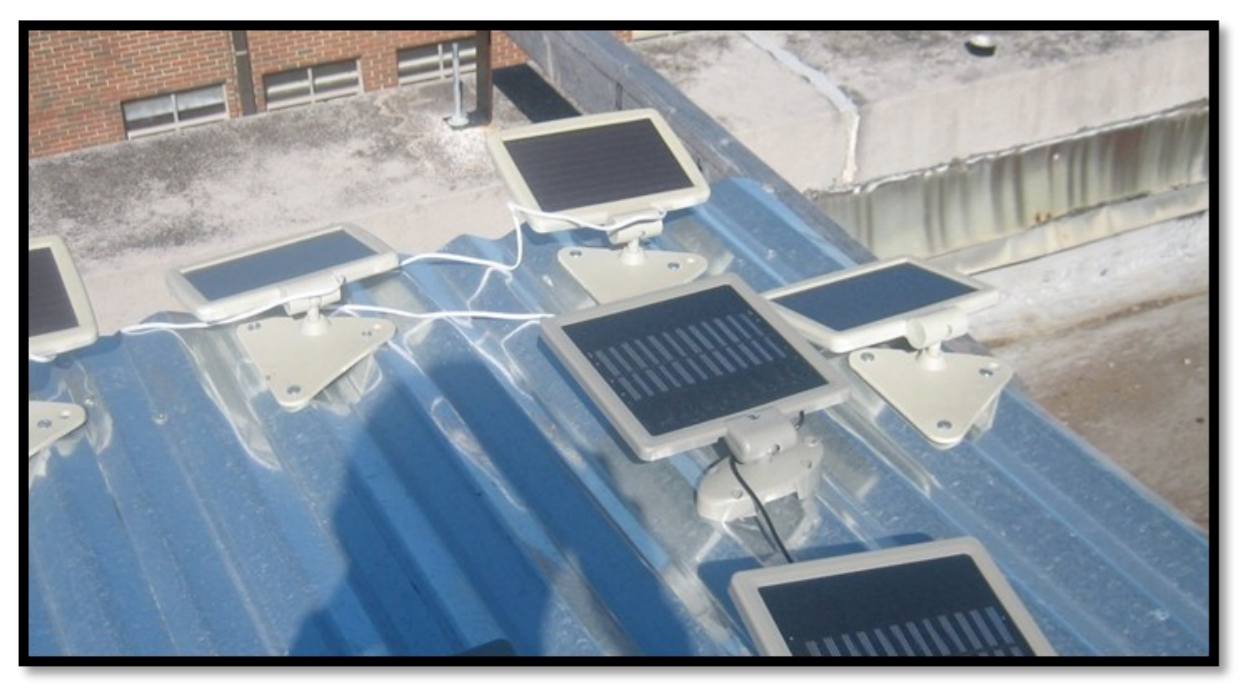

FIGURE 18

SUNFORCE PANELS UNABLE TO MAINTAIN ANGLES.

Overall, it seems that all panels are quite durable. When the testing period ended, it looked as if they suffered no ill effects from the elements such as rain and wind during this three month trial. The lights also appear to be durable, although they did not endure any weather exposure like the panels. Preferably these lights should be installed under the roof of a community building. During the tests some lights were accidentally dropped, and the Sunforce lights did the best. The LED bulb guard only came off when it was intentionally removed, and its batteries can only be removed with a screwdriver. The LEDtronics, Inc. lanterns' batteries have been installed at the bottom and the bottom piece that secures the battery tends to come off when dropped leaving the battery exposed. It is very simple to put it back on, but the battery could suffer damage if exposed to water. The Designers Edge lights did dismantle quite easily after being dropped, but they more than likely will not be in such situations if installed properly. After the lights had been dropped, they did continue to generate light and did not seem affected.

Cleaning of the panels was a big concern for this study. The panels are meant to be installed in such a manner that the users (villagers) will have as little interaction with them as possible, so the panels were not cleaned during the study. There is no evidence to support whether or not they were affected by the presence of dust, but there was enough rain to keep these panels somewhat clean. If these systems were damaged or quit working while they were being used they could be fixed rather easily, but it may take days or weeks to get the supplies necessary to fix the problem from the Ngo who make weekly rounds to villages. There was no failure witnessed as far as the panels were concerned, but it did occur with the lights. None of the panels or lights experienced any type of corrosion, because they are made mostly of plastic.

TABLE V

On-Site Operation and Maintenance Ratings

\begin{tabular}{|l|c|l|l|l|l|}
\hline & $\begin{array}{c}\text { Contribution } \\
\text { to Total (\%) }\end{array}$ & Weight (\%) & $\begin{array}{l}\text { LEDtronics, } \\
\text { Inc. }\end{array}$ & Sunforce & $\begin{array}{l}\text { The Designer's } \\
\text { Edge }\end{array}$ \\
\hline On-Site & 15 & & & & \\
\hline
\end{tabular}




\begin{tabular}{|c|c|c|c|c|c|}
\hline Operation & & & & & \\
\hline Ease of Installation & & 3 & 66 & 100 & 100 \\
\hline Usability & & 2 & 100 & 100 & 100 \\
\hline Mobility & & 1 & 100 & 100 & 0 \\
\hline Adjustable Angle & & 2 & 0 & 100 & 100 \\
\hline Keep Angle? & & 2 & 0 & 100 & 100 \\
\hline $\begin{array}{l}\text { Equipment } \\
\text { Durability }\end{array}$ & & 3 & 66 & 100 & 33 \\
\hline Weather Damage & & 2 & 100 & 100 & 100 \\
\hline Subtotal & & & 8.96 & 15.00 & 11.99 \\
\hline Maintenance & 15 & & & & \\
\hline Require Cleaning & & 3 & 100 & 100 & 100 \\
\hline Easily Fixed & & 4 & 100 & 100 & 100 \\
\hline Failure & & 4 & 33 & 100 & 50 \\
\hline Corrosion & & 4 & 100 & 100 & 100 \\
\hline Subtotal & & & 12.32 & 15.00 & 13.00 \\
\hline
\end{tabular}

\section{Sustainability and Environmental Impact}

Sustainability and environmental impact accounted for $10 \%$ of the final score, broken down ito output consistency ( $3 \%)$, rate of replacement (4\%), and battery toxicity $(3 \%)$.

As a whole, it seems thet if the system initially operates correctly "out of the box" then it will likely be very reliable. Throughout testing the lights were able to generate consistent amounts of illuminance. The panels also produced steady quantities of power throughout testing. Product performance quality was fairly consistent across each product tested. It is dependent on weather. As far as rate of replacement is concerned, these panels come with warranties to substantiate that they should last over a year's time. The Designers Edge system is the only system that guarantees over one year of use.

All of the systems have batteries that have potential to be hazardous if they are not properly disposed. They can potentially corrode and poison their users if handled improperly. Users must dispose of of the batteries properly, and conversations are underway with the NGO to try to setup a system of safe replacement and disposal. The LEDtronics, Inc. system will receive a score of 0 out of 100 since it houses a large lead-acid battery, a serious disposal problem. The other two systems will receive 0.5 scores because their lights use smaller Ni-Cd batteries. It is possible that these batteries could be replaced with NiMH batteries that are somewhat safer, but they require a special charging cycle. The scores can be seen on Table VI.

TABLE VI

Sustainability and EnVironmental Impact Ratings

\begin{tabular}{|c|c|c|c|c|c|}
\hline & $\begin{array}{l}\text { Contribution } \\
\text { to Total }(\%)\end{array}$ & $\frac{\text { Weight }}{(\%)}$ & $\begin{array}{l}\text { LEDtronics, } \\
\text { Inc. }\end{array}$ & $\underline{\text { Sunforce }}$ & $\frac{\text { The Designer's }}{\text { Edge }}$ \\
\hline $\begin{array}{l}\text { Sustainability and } \\
\text { Environmental Impact }\end{array}$ & 10 & & & & \\
\hline Output consistency & & 3 & 100 & 100 & 100 \\
\hline Rate of Replacement & & 4 & 70 & 90 & 100 \\
\hline Battery toxicity & & 3 & 0 & 0.50 & 0.50 \\
\hline
\end{tabular}




\begin{tabular}{|l|l|l|l|l|l|}
\hline Subtotal & & & 5.80 & 6.62 & 7.02 \\
\hline
\end{tabular}

\section{Learning Outcomes Assessment}

Students on the 2008 solar panels installation trip participated in a formal post-trip assessment. Students scored elements of the experience using the five-level Likert scale to evaluate 12 course elements that included ABET outcomes. In addition, the students were asked four open-ended questions that allowed for both qualitative assessments and additional comments.

The average score of 4.8 (Table VII) is quite high, indicating strong agreement that the course was a valuable learning experience. Among the outcomes that serve as an assessment basis for engineering accreditation, students agreed strongly that it was an effective learning experience with regard to communication, learning outside the classroom, teaming, and assessment of societal impacts. They agreed, but not as strongly, that it was a valuable learning experience regarding leadership.

In the qualitative section of the survey, students were asked to identify five areas of learning not found in a traditional classroom. They were also asked about challenges, unexpected events, and personal growth. Five students provided eight responses each for a total of 40 comments.

Of these responses seven dealt with communications, particularly the challenges and successes with technical communications given limited language skills and non-technical clients. Example: "The form of communication didn't matter as long as the ideas were able to cross the language barrier." Five more responses dealt with cultural issues. Example: "Developing countries don't really run on a schedule, but still manage to get things done." Four responses addressed positive aspects of teaming. Examples: "Being an effective supportive member of a group." "The area in which I grew most was working as part of a team and communicating effectively." Three more dealt with ingenuity. Examples: "I learned to look for alternative and nontraditional methods to accomplish tasks." "How to make things work with what you have." "About solar panels and how to install them."

Others addressed leadership, coping, personal growth, and the value of international travel. Examples: "Helped reinforce leadership skills." "I could make it without everyday luxuries like electricity and toilets." "If I push myself I can do things I never imagined." "I grew most in the knowledge of international traveling. Even though I had been overseas before, this trip was a much better experience. We were given more responsibilities ... . I was happy to grow in this area because of my very big interest in traveling and seeing the world."

While the number of students evaluating their experience is low, their assessment is consistent with feedback the instructors have received over and over again following similar service learning trips. Learning outside the classroom box is the real deal, our students continually tell us. And teaching outside that box has similar rewards for faculty.

Future assessments will include a pre-trip evaluation to better measure learning outcomes. A question will also be added to solicit suggestions for future trips rather than leave this as an implied question under "other comments," though when asked if they would recommend this trip to others, three gave it a 5 (strongly agree) one a 10 and one " 5 x 1000 !"

\section{TABLE VII}

\section{Course Outcomes Assessment}




\begin{tabular}{|c|c|c|}
\hline Specific Course Learning Outcomes & \multirow[t]{2}{*}{ 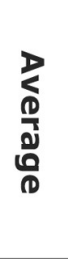 } & \multirow[t]{2}{*}{ 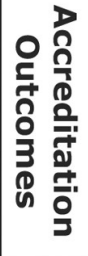 } \\
\hline This trip was a valuable learning experience with respect to: & & \\
\hline functioning as a member of a team. & 4.6 & $\square$ \\
\hline developing leadership skills. & 4.0 & 口 \\
\hline developing organizational and communication skills. & 5.0 & $\mathbf{\square}$ \\
\hline experiential learning without the aid of formal instruction. & 5.0 & $\mathbf{\square}$ \\
\hline \multicolumn{3}{|l|}{ examining possible/actual economic, environmental, and societal } \\
\hline impacts of a specific, relatively constrained engineering solution. & 4.8 & $\square$ \\
\hline project management in an international setting. & 4.8 & \\
\hline \multicolumn{3}{|l|}{ understanding the importance of stakeholder (village) input to } \\
\hline project planning, scheduling, and/or installation. & 4.6 & \\
\hline professional career development. & 4.8 & \\
\hline experiencing another culture. & 5.0 & \\
\hline my own personal growth experiences. & 5.0 & \\
\hline expanding my view of the developing world. & 5.0 & \\
\hline I would recommend this trip to peers. & 5.0 & \\
\hline Overall Average & 4.8 & \\
\hline \multicolumn{3}{|l|}{5 strongly agree, 4 agree, 3 neutral, 2 disagree, 1 strongly disagree } \\
\hline
\end{tabular}




\section{Conclusion and Future Work}

In this study we examined three different PV systems and assessed them according to the traits needed in rural areas of developing countries. As can be seen from the overall scores in Table VIII, the Sunforce and Designers Edge systems are effectively tied, and both are deemed acceptable for large scale installation. The LEDtronics, Inc. is not deemed appropriate, both because of it's substantially lower overall score and because of the lead-acid battery.

The UA relationship with the community and NGO is long term. The ongoing feedback from the NGO is that the lights are working and that the villagers are happy with them. In our followup trip in the summer of 2010 we will collect further feedback from villagers, inspect the systems installed in 2008, and expand the installation of the two best performing systems throughout the community.

In the villages, town meetings and individual interviews will be held to obtain further feedback on the installed systems. From a technological standpoint it is important to determine what the lights are used for, if the lamps have increased or decreased light production, if any of the lights have broken, if the panels have stayed where they were installed, etc. And from a sociological standpoint, there are questions of lifestyle changes,

pride of ownership, training, maintenance, recycling, etc. In short, do the lights make life better in the villages? And, do they have sufficient value that the villagers would be willing to pay part or all of the costs of future installations?

Finally, there is the question of sustainability. The authors are still collecting data to determine the effective life of the lamps, and a critical feature of this year's visit will be to develop a clear idea of the costs of repair and replacement in such a remote area. Given that information, it will be possible to develop a lifecycle cost, and investigate means to fund continued lighting of the villages. Such means include, funding by the villages themselves, or donor funds. In the interim, to promote sustinability, our NGO will manage the defective parts (battery, panel or light module) replacement program. We are also collaborating with the NGO on an emerging sustainable battery recycling initiative, for all batteries including solar system batteries.

Assessment of the effectiveness of the experience was structured around ABET assessment outcomes, course-specific outcomes, open-ended questions to the students, and student products such as journals, research reports, designs, and presentations. Student responses on 5 point Likert-scale surveys averaged 4.8 across all questions indicating strong positive agreement on the effectiveness of the course, and that perspective was also reflected in their responses to the open-ended questions.

\section{Acknowledgments}

This study was made possible by support from the National Science Foundation GK-12 program Grant \# 0742504. Thanks also go to the UA Engineering technicians Doug Cannon, Tim Ryan, and Evan Hisey for their work on the project. 
TABLE VIII

Weighing and Scoring Table

\begin{tabular}{|c|c|c|c|c|c|}
\hline Performance Criteria & $\begin{array}{c}\% \\
\text { Contribution } \\
\end{array}$ & Weight (\%) & LEDtronics & Sunforce & $\begin{array}{c}\text { Designer's } \\
\text { Edge }\end{array}$ \\
\hline Panel Performance & \multirow[t]{7}{*}{30} & \multirow[b]{6}{*}{20} & & & \\
\hline Clear Conditions & & & 100 & 75 & 70 \\
\hline Overcast Conditions & & & 100 & 75 & 65 \\
\hline Cloudy Conditions & & & 100 & 90 & 80 \\
\hline Precipitation Event & & & 80 & 50 & 60 \\
\hline Overall Panel Performance & & & 95 & 72.5 & 68.75 \\
\hline$\$ /$ Wattage (Peak 2 Hour Period) & & 10 & 66 & 33 & 100 \\
\hline Subtotal & & & 25.60 & 17.80 & 23.75 \\
\hline
\end{tabular}

\begin{tabular}{|l|c|c|c|c|c|}
\hline Light Performance & \multirow{2}{*}{30} & & & & \\
\hline Unit Failure Rate & & 15 & 60 & 100 & 90 \\
\hline Consistency of Systems' Lights & & 4.5 & 33 & 100 & 66 \\
\hline Overall Production & & 10.5 & 57 & 86 & 100 \\
\hline Subtotal & & & $\mathbf{1 6 . 4 7}$ & $\mathbf{2 8 . 5 3}$ & $\mathbf{2 6 . 9 7}$ \\
\hline
\end{tabular}

\begin{tabular}{|c|c|c|c|c|c|}
\hline On-Site Operation & 15 & & & & \\
\hline Ease of Installation & & 3 & 66 & 100 & 100 \\
\hline Usability & & 2 & 100 & 100 & 100 \\
\hline Mobility & & 1 & 100 & 100 & 0 \\
\hline Adjustable Angle & & 2 & 0 & 100 & 100 \\
\hline Keep Angle? & & 2 & 0 & 100 & 100 \\
\hline Equipment Durability & & 3 & 66 & 100 & 33 \\
\hline Weather Damage & & 2 & 100 & 100 & 100 \\
\hline Subtotal & & & 8.96 & 15.00 & 11.99 \\
\hline
\end{tabular}

\begin{tabular}{|c|c|c|c|c|c|}
\hline Maintenance & 15 & & & & \\
\hline Require Cleaning & & 3 & 100 & 100 & 100 \\
\hline Easily Fixed & & 4 & 100 & 100 & 100 \\
\hline Failure & & 4 & 33 & 100 & 50 \\
\hline Corrosion & & 4 & 100 & 100 & 100 \\
\hline Subtotal & & & 12.32 & 15.00 & 13.00 \\
\hline
\end{tabular}

\begin{tabular}{|l|c|c|c|c|c|}
\hline \multirow{2}{*}{ Sustainability \& Environmental Impact } & \multirow{2}{*}{10} & & & & \\
\hline Keep the same rates & & 3 & 100 & 100 & 100 \\
\hline Rate of Replacement & & 4 & 70 & 90 & 100 \\
\hline Battery toxicity & & 3 & 0 & 0.50 & 0.50 \\
\hline Subtotal & & & $\mathbf{5 . 8 0}$ & $\mathbf{6 . 6 2}$ & $\mathbf{7 . 0 2}$ \\
\hline Total Score & $\mathbf{1 0 0}$ & $\mathbf{1 0 0}$ & $\mathbf{6 9 . 1 5}$ & $\mathbf{8 2 . 9 5}$ & $\mathbf{8 2 . 7 3}$ \\
\hline
\end{tabular}




\section{REFERENCES}

[1] Johnson, P.D., P.W. Johnson, and N. Shaney, “The Development of Contemporary Engineering Skills through International Service Learning in Peru." J. of Community Engagement and Scholarship (2008) 2(1) 48-52.

[2] Messenger, R. \& D. Yogi Goswanni, "Photovoltaics Fundamentals, Technology and Application," in Handbook of Energy Efficiency and Renewable Energy (Mechanical Engineering) (Boca Raton: CRC, 2007), 23-13.

[3] Petchers, N. "Renewable \& Alternative Power Technologies," in Combined Heating, Cooling \& Power Handbook: Technologies \& Applications (Lilburn: Fairmont, 2003).

[4] "History: Weather Underground. " Tuscaloosa Airport. 2009. Weather Underground. 20 Sept. $2009<\mathrm{http}: / / \mathrm{www}$. wunderground. com/history/airport/KTCL/2009/11/9/DailyHistory. html? req_city $=\mathrm{NA} \&$ req_state $=\mathrm{NA} \&$ req_statename $=\mathrm{NA}>$.

[5] "Seasonal Weather Averages : Weather Underground. " Iquitos Airport. 20 Sept. 2009. $<$ http:/www. wunderground. com/NORMS/DisplayIntlNORMS. asp? CityCode $=84377 \&$ Units $=$ english $>$.

[6] "Surface meteorology and Solar Energy." NASA Langley Atmospheric Science Data Center (Distributed Active Archive Center). 20 Sept. 2009. <http://eosweb. larc. nasa. gov/sse/>.

[7] Griffis, F.H., J. V. Farr, and M.D. Morris, Construction Planning for Engineers, McGrawHILL, 1999. ISBN 0073033278. 